DOE/ER-0025-D

\title{
DRAFT
}

\section{The Nuclear Strategy of the Department of Energy}

September 26, 1978

Editorial Revisions: February 15, 1979

Published April 1979

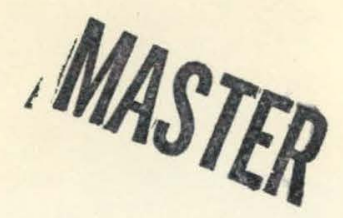

U.S. Department of Energy

Office of Energy Research

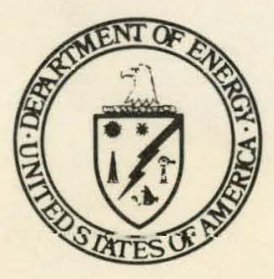




\section{DISCLAIMER}

This report was prepared as an account of work sponsored by an agency of the United States Government. Neither the United States Government nor any agency Thereof, nor any of their employees, makes any warranty, express or implied, or assumes any legal liability or responsibility for the accuracy, completeness, or usefulness of any information, apparatus, product, or process disclosed, or represents that its use would not infringe privately owned rights. Reference herein to any specific commercial product, process, or service by trade name, trademark, manufacturer, or otherwise does not necessarily constitute or imply its endorsement, recommendation, or favoring by the United States Government or any agency thereof. The views and opinions of authors expressed herein do not necessarily state or reflect those of the United States Government or any agency thereof. 


\section{DISCLAIMER}

Portions of this document may be illegible in electronic image products. Images are produced from the best available original document. 


\section{DRAFT}

\section{The Nuclear Strategy of the Department of Energy}

September 26; 1978

Editorial Revisions: February 15, 1979

Published April 1979

\section{U.S. Department of Energy}

Office of Energy Research

Washington, D.C. 20545

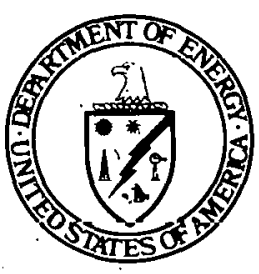

$$
\begin{aligned}
& \text { This report was prepared as an account of work } \\
& \text { sponsored by the United States Govemment. Neither the } \\
& \text { United States not the United States Department of } \\
& \text { Energy, nor any of their employees, nor any of their } \\
& \text { contractors, subcunuractors, or their employees, makes } \\
& \text { any warranty, express or implied, or assumes any legal } \\
& \text { liability or responsibility for the accuracy, completeness } \\
& \text { or usefutness of any information, apparatus, product or } \\
& \text { process disclosed, or represents that its use would not } \\
& \text { infringe privately owned rights. }
\end{aligned}
$$


THE NUCLEAR STRATEGY OF THE DEPARTMENT OF ENERGY

OFFICE OF ENERGY RESEARCH

DEPARTMENT OF ENERGY

SEPTEMBER 26, 1978

Editorial Revisions: February 15, 1979

\section{CONTENTS}

SECTION

$\underline{\text { TITLE }}$

$\underline{\text { PAGE }}$

Executive Summary

i

I

Introduction and Purpose

1

II

The Need for Nuclear Power

3

III

Conceptual Framework for the Analysis

5

IV

Analysis

11

V

Alternative Nuclear Strategies

37

VI

Program Implementation of the Strategy

51

Appendix A

Model Results

61 
The purpose of this paper is an analysis of the important technical and economic parameters related to the timing and future deployment of nuclear power in the U.S. The analysis is used first to form the basis of a set of alternative nuclear strategies and then to assist in a critical evaluation of these strategies. The strategies involve major decisions on breeder commercialization, fuel cycle development, and strengthening the nuglear option in the U.S.

DOE energy projections indicate that nuclear power must play a. substantial role in meeting future U.S. energy needs, even under assumptions that are optimistic with respect to energy conservation and the increased use of coal-fired generating plants. Also, estimates indicate that nuclear. power can have a substantial cost advantage in certain areas of the U.S. However, these estimates involve significant uncertainties, such as the relative environmental impact of the nuclear and coal cycles and the costs of meeting new environmental performance standards.

There are three main elements in the fission portfolio:

- programs which extend the uranium resource base or which add to the efficiency of its use;

o breeder programs; and

- enabling programs. 
The key to analyzing this portfolio is the breeder reactor. The principal questions are whether a transition to breeder reactors becomes necessary, and if so, at what date. The breeder reactor represents a technology that expands nuclear fission from an exhaustible to an inexhaustible enërgy source.

Two different models form the basis of the analysis:

- The Finite Ore Model which assumes a fixed uranium ore base and analyzes when the resource base has been committed to light water reactors (LWRs) and advancèd converter reactors (ACRs).

- The Economics Model which analyzes time frames in which no further uranium is available at a price below that : which makes breeder reactors economically competitive with LWRs and ACRs.

For these models, the date of transition is a function of the amount of uranium ore available, the growth of nuclear generating capacity, the relative costs of competing systems and the effiçiency with which the uranium is used in thermal reactors. These variables are treated para-. metrically in the analysis.

The analysis considers four different cases made up of five different reactor systems: the standard light water reactor, an improved LWR (15 percent savings in fuel use), an optimized LWR ( 25 percent savings in fuel use), an advanced converter reactor, and a breeder. In the four cases, the first four types of reactors are introduced in varying combinations, based on technical judgments as to when these systems will be ready for deployment: The breeder reactor introduction date is then 
determined as an output of the analysis, based on total commitment of the uranium resource base in the Finite Ore Model and on achievement of economic competitiveness in the case of the Economics Model.

The lifetime ore requirements in the four cases are based on the current tails assay of $0.2 \%$ from the uranium enrichment facilities. This tails assay could be reduced to as low as $0.05 \%$ at existing or planned. facilities, or through advanced isotope separation techniques. The lower. tails assay would reduce LWR or ACR ore requirements by approximately. $20 \%$. Each of the four cases was also analyzed on the basis of the $0.05 \%$ tails assay being employed in the mid-1990's. ,

The projected growth in nuclear power is the single most important parameter in the development of a sound strategy. Recognizing the uncertainties in such projections, a wide range of growth patterns were incorporated in the analysis. The installed capacity by the year 2000, spanning DOE high and low estimates, was as sumed at levels of $200 \mathrm{GWe}, 300$ GWe, and $40.0 \mathrm{GWe}$, with subsequent annual additions in the 21 st century of $10 \mathrm{GWe}, .15 \mathrm{CWe}$, and $20 \mathrm{GWe}$.

A range in the size of the uranium resource base was also employed. For the Finite Ore Model, values of $1.8,3.6$, and 4.5 million tons were chosen, the higher value being approximately equal to the current. NURE estimate of resources available in the U.S. below $\$ 50 / 1 b$. forward cost. In the Economics Model price-quantity supply curves are used, reflecting greater quantities of ore availability. at higher costs.

Finally, for the Economics Model, it was necessary, to make use of the relative costs of the various reactor systems. Initial indications are that the capital cost of the improved and optimized LWR will not 
differ substantially from the standard LWR. The capital cost of the breeder was assumed to be from $25 \%$ t.o $75 \%$ higher than that of the reference LWR. The fuel cost was assumed to follow the uranium cost/supply curves mentioned above.

The major observations derived from the results of the Finite Ore Model calculations are:

- If the ore base is only 1.8 million tons, breeder reactoro must be introduced arnind the yoar 2000 .

- If the ore base is 3.6 million tons, the introduction of the breeder can be delayed until the period 2010-2050. The earlier date is associated with the highest nuclear growth rate and the deployment of only the standard LWR. The later date results from the use of the lowest nuclear growth rate, the introduction of LWR improvements, introduction of an ACR, and achievement of a $0.05 \%$ tails ạs say .

- With the large ore base, the breeder is not required until earlier than 2015 and possible as late as second half of. the century (under as sumptions parallel to those in the medium ore base case).

- The introduction of both the improved and optimized LWR showe marked effects (Iive to cight years of addiliurial generating capacity) in all but the low ore base case. The introduction of an ACR around 1995 would stretch the ore exhaustion date by an additional three to seven years. 
The major observations to be drawn from the calculations performed using the Economics Model are:

- For. a breeder with capital costs 1.25 times an LWR, an economic transition date would occur as early as 1997 for the highest assumed uranium costs, and the highest nuclear growth rate, and as late às 2025 for the case using intermediate uranium costs and the lowest nuclear growth rate.

- For a breeder with capital costs 1.50 times an LWR, the economic transition date would occur in 2007 for the highest uranium costs and highest nuclear'growth rate, and later than 2025 for the intermediate uranium cost and lowest growth rate.

- For a breeder with capital costs 1.75 times the reference LWR, there is virtually no set of assumptions about uranium supply or nuclear growth that would lead to an economic transition to the breeder before 2025 .

- For all the above combinations, application of the lower tails assay extends the economic transition date between three to seven years.'

- Introduction of the improved LWR can delay the economic transition from five to ten years. The subsequent introduction of the optimized LWR can delay the transition an additional three to ten years. 
Alternative strategies have been examined that are consistent with a range of proposed approaches for developing the nuclear option and meeting the nuclear energy demand. The strategies are based on types of nuclear reactors as the main thrust. The supporting fuel cycle work is a derivative of the mainline reactor program.

In every strategy, priority is given to waste management because the achievement of progress in this area is considered essential to resolving a large element of uncertainty in the nuclear program. The strategies are as follows:

Strategy 1: Early Breeder. This strategy is based on the view that the uranium ore hase is 1 imitcd, that the inulear growth rate will be high, and/or that breeder economics will be very favorable. The strategy calls for an early commitment to the breeder, with completion of a conceptual design study by 1981 , commitment to a demonstration facility by 1982 , and initial commercial deployment in 20 years thereafter. Reprocessing development would be given high priority through commercialization. and the programs for LWR improvement, ACR development, Advanced Isotope Separation Technology (AIST), and the National Uranium Resource Evaluation (NURE) program would be deemphasized. This stratcgy would creale a relacively high cost program that would also have moderately high risks in being successful with breeder dppl syment.

Strategy 2: Late Breeder. This strategy is based on the view that the resource base is adequate for a long period of LWR once-through operation, that the nuclear growth rate will be low, and/or that breeder economics will be unfavorable. Consequently, commercialization of the 
vii

breeder is deferred as long as possible. Breeder development is pursued at a low level. A decision on a demonstration plant is deferred until the $1990^{\circ}$. Reprocessing development is deferred. LWR improvements, ACR development, AIST, NUURE, and centrifuge facility deployment and development are emphasized.

Strategy 3: Hedged Breeder. This strategy is consistent with a view that the resource base, nuclear growth, and breeder economics can be reasonably judged to have values that do not require rapid progression to the breeder. However, recognizing that there is a substantial uncertainty about this judgment, the strategy maintains sufficient flexibility and options so that program shifts can be made easily and effectively whenever information or events dictate. The programs for LWR improvement, ACRs, AIST, NURE, and centrifuge facilities are emphasized, but"are less strongly supported than in Strategy 2. Breeder development continues at a moderate level with emphasis on engineering and component development. A decision on a demonstration plant could be taken in 1981; but also could be deferred until 1986-1990. Plans for both a 20-year and a 30-year commercialization progran could be developed. Reprocessing technology is developed but commercialization is deferred. This is a balanced program that attempts to'minimize risk at a moderate cost.

Strategy 4: Expanded Nuclear. In this view, nuclear power will play a predominant role in our energy future, with installed capacities at least equal to the highesl values aoeumed in the analysis. Aggressive programs would be pursued for LWRs, ACRs, and breeders with commitments to 
viii

commercialize at the earliest possible dates. For the breeder, this would call for a decision on a demonstration plant in 1981 and planning for both a 20-year and a 30-year deployment schedule. Reprocessing, through the commercialization stage, would be accelerated. The program would be very costly but would provide the greatest assurance of maintaining and deploying the nuclear option.

Evaluation of the results of the analysis and the above strategies

leads to the following main conclusions:

o Both the Finite Ore Model and the Economics Model resulte

show that the achievement of assumed LWR improvements, ACR deployment, or lower tails assay can make worthwhile contributions to the nuclear economy. When all or part of these achievements are combined in various ways, the contribution becomes quite significant.

- l'he transition to the breeder reactor can be delayed for a number of years. Only when high nuclear growth, low uranium resources, and low breeder capital costs occur simultaneously is there justification for early breeder introduction.

- Based on the probable ranges of the key variables and likely technological development,paths, the analysis shows that the large majority of Lhe 54 cases treated by the Economic Model project an economic transition to the breeder after the year 2025. However, there are 
a number of significant situations in which the breeder would be needed between 2010 and 2025. There are few situations which indicate a transition before 2010 .

o A strategy to delay. the decision to build a breeder demonstration reactor is the most consistent with the largest space of future events analyzed in this study. However, because of the number of situations wherein a breeder would be needed between 2010 and 2025, it is prudent to pursue a strategy that continues: extensive development of breeder design and components. Strategies to move forward rapidly with breeder development are not supported by the analysis. 


\section{INTRODUCTION AND PURPOSE}

Civilian use of nuclear energy continues to be a matter of great concern for the public, for Congress, and for both, domestic and international bodies. These concerns span a range from a serious national need for expandable energy sources to just as serious concerns for non-proliferation, radioactive waste management, and the environment. A combination of such concerns, along with reduced needs for electric power and plant construction delays, has resulted in a steadily decreasing projected deployment of nuclear power (by a factor of three in the last six years in the U.S.) both in the U.S. and abroad.

Notwithstanding the concerns over nuclear power, serious constraints on the use of oil and gas for electrical power generation, coupled with the environmental problems of coal power plants, render nuclear an attractive alternative for electrical generation in this Nation's future. However, as a result of the reduced nuclear power demand and the growing concerns over the potential spread of sensitive nuclear materials, there has not been a necessity to make immediate decisions regarding near-term reprocessing and breeder commercialization, from either an economic or resource perspective.

Programs which formed the basic thrust of nuclear development in the early 1970's have to some extent already been adjusted in view of present realities. To date, this adjustment process has taken the form of: 
- Increased emphasis on problems of radioactive waste management, especially provisions for away-from-reactor storage and developing technology options for ultimate disposal of radioactive wastes.

- Increased attention to the non-proliferation objectives and reorientation of the reprocessing, fuel cycle, and brceder pruyrams.

- Increased emphasis on once-through light water reactor technology.

- Increased concern for more detailed knowledge of the uranium resnurce bacc.

- Reorientation of the uranium enrichment programs to coincide with the pace and scope compatible.with anticipated demand for enrichment services.

- Exploration of fuel cycles (such as thorium) which minimize the use of plutonium.

Nevertheless, major strategic decisions still loom over breeder commercialization, the breeders' requisite demand for reprocessing, and the future role of more proliferation-resistant nuclear technologies. These decisions require long lead-times for deployment and must be planned decades in advance.

In consequence, one of the major objectives of DOE is to assure that the transition continues in an intelligent and orderly manner, preserving those options needed for the necessary decisions of the future. The principal focus of this paper is an analysis of the important technical and 
economic parameters related to the future of nuclear power in the U.S. The analysis is used first to form the basis of a set of alternative nuclear strategies suitable for the United States and then to assist in a critical evaluation of these strategies. The strategies offer a set of different nuclear futures approached from differing assumptions and differing viewpoints. They should be useful for a wide range of policy makers .

The nuclear strategies presented and discussed here are not fixed for all time nor are they designed to cover all future contingencies. Rather, any selected strategy. must be continually examined, reevaluated, and built upon over time. Of necessity, the strategy must have the flexibility to anticipate and accommodate potential shifts in our knowledge about future events (a narrowing of uncertainties) as well as the capability to adapt to emerging technology.

\section{THE NEED FOR NUCLEAR POWER}

It is apparent that nuclear energy must play a part in meeting our future energy needs under any plausible set of assumptions. DOE's best estimates of Llie total elertrical generation capacity by energy source that will be installed between now and the year 2000 are given in Table 1. Even under assumptions that are optimistic with respect to both energy conservation in the United States and the increased use of coal-fired electrical generation plants, it appears that nuclear power will be a major contributor in our Nation's energy tuture. It should he emphasized that these projections are based on reasonable assumptions 
TABLE 1

INSTALLED U.S. GENERATING CAPACITY (GWe) 1 '

$\frac{\text { Nuclear } \underline{2} /}{\text { High } \underline{3} \text { Low }}, \frac{\text { Cool }}{\text { High Lch }} \quad \frac{\text { Gas }}{\text { High Low }} \frac{\text { Oil }}{\text { High Low }} \frac{\text { Hydro }}{\text { High Low }} \frac{\text { Other }}{\text { High Low }}$

\begin{tabular}{|c|c|c|c|c|c|c|c|c|c|c|c|c|}
\hline \multirow{2}{*}{$\begin{array}{l}1977 \\
1980\end{array}$} & \multirow{2}{*}{$\begin{array}{l}49 \\
66\end{array}$} & t & \multicolumn{2}{|c|}{213.6} & \multicolumn{2}{|c|}{78.8} & \multicolumn{2}{|c|}{140.3} & \multicolumn{2}{|c|}{68.5} & \multicolumn{2}{|c|}{11.2} \\
\hline & & 62 & 258 & 245 & 80 & 80 & 151 & 151 & 78 & 78 & 12 & 12 \\
\hline 1985 & 122 & 100 & 296 & $2 ? ?$ & 83 & 79 & 178 & 171 & 92 & 92 & 19 & 19 \\
\hline 990 & 192 & 157 & 395 & 328 & 87 & 76 & 185 & 175 & 105 & 105 & 25 & 25 \\
\hline 2000 & 395 & 255 & 585 & 435 & 85 & 70 & 190 & 175 & 115 & 115 & 50 & 50 \\
\hline
\end{tabular}

I/ The proposed National Energy Act is not entirely reflected in these projections. The Act encouräges and/or mandates the shift away from oil and gas to coal.

2/ Preliminary data $\tilde{i}$ rot. EIA indicate that these numbers will be revised. downward in tie 1979 projections.

3/ Based on EIA Series F through 1990 which assumes medium demand, medium supfly: and increasing world oil prices.

4/ Based on EIA Series E through 1990 which assumes low supply,.. low demand, and constant world oil price. 
concerning the continued acceptance of nuclear power and the rate of expansion of coal generating capacity.

In addition, our estimates indicate that nuclear power will have a substantial cost advantage over coal in providing electricity, particularly in New England and the Mid-West. A comparison of the relative costs of coal and nuclear in these regions is given in Table 2.

The table contains the capital costs and generation costs of producing power from a 1000 MWe coal-fired plant in comparison to a $1000^{\circ}$ Me nuclear plant. The costs in the table are not average costs of existing capacity but reflect the marginal costs to the consumer of these plants in three different time periods: 1975, 1985, and the year 2000 .

The figures in Table 2 are based on a series of economic assumptions. There is uncertainty in these assumptions, for example, about the future costs of waste disposal or the costs of meeting new source performance standards. In addition to these economic uncertainties, there exists even. greater uncertainties on the relative overall environmental impact of the nuclear. cycle in comparison to coal cycle. The uncertainties concerning the relative environmental effects of these two technologies become progressively more severe as one assesses the overall global impact of liaving the technology in operation over many decades on a substantial scale.

\section{III. " CONCEPTUAL FRAMEWORK FOR THE ANALYSIS}

The framework developed for the analysis in this paper is intended to facilitate decisions on investment in each element of DOE's fission portfolio for FY 1980 and on the investment trend in subsequent years. 
COSTS OF TYPICAL 1000 MWe PLANT

(Constant 1975 Dollars)

\section{$1975^{a}$}

$\underline{\text { Coal }}$

$\begin{array}{cc}\text { With } & 1985^{\mathrm{b}} \\ \begin{array}{c}\text { Sithout } \\ \text { Scrubbers }\end{array} & \text { Scrubbers }\end{array}$

311.0
7.7
8.5
1.6

17.8

$$
\begin{array}{r}
555.0 \\
13.7 \\
12.0 \\
2.8 \\
28.5 \\
\\
667.0 \\
15.5 \\
5.4 \\
2.0 \\
2 \Xi .9
\end{array}
$$

Nuclear (LWR)

$\begin{array}{crrr}\text { Capital Cost } & & \\ & -\$ / \mathrm{kW} & 374.0 & 667.0 \\ \text { Fuel Cycle } & -\mathrm{mills} / \mathrm{khh} & 9.2 & 15.5 \\ & & 2.6 & 5.4 \\ \text { O\&M } & -\operatorname{mills} / \mathrm{kWh} & 2.0 & 2.0 \\ \text { Total } & -\operatorname{mills} / \mathrm{kWh} & 13.8 & 23.9\end{array}$

465.0

10.3

15.3

1.6

27.2

44

a. Steam Electric Plant Construction Cost and Annual Production Experses, 1975, Twenty-Eight Ann:al Supplerent. January 1978 (DOE/EIA-0033/1) (Assumptions: Fixed Charge of 13\%, Capacity Factor of $60 \%$ ).

b. Nuclear Power Issues and Choices, Ford FoundationiMitre Corporation, January 11, 1977 (p. 3-31).

c. Study Panel Irexhaustible Energy Resources Study, U.S. ERDA, September 1977 (p. 3- $\varepsilon$, average of 1990 and 2010 data). 
There are three main elements in the fission portfolio:

1. programs which extend the uranium resource base (National Uranium Resource Evaluation (NURE)', Advanced Isotope Separation Technology (AIST), and enrichment) or which add to the efficiency of its use (Light Water Reactor (LWR) improvement and Advanced Converter Reactor (ACR) development);

2. breeder programs; and

3. enabling programs (waste management, transportation, environment, nonproliferation, health, and safety).

The key to analyzing this portfolio is the breeder. The principal questions are whether a transition to breeder reactors becomes necessary, and if so, at what date. The breeder reactor represents a technology that expands nuclear fission from an exhaustible to an inexhaustible energy technology. It is the largest item in the fission energy budget. As is well known, it is the center of heated political controversy both in the U.S. and internationally.

\section{A. Analysis concepts}

The analysis centers around two different models--a Finite Ore Model and an Economics Mode1. The Fintte Ore Mode1 assumes a fixed uranium ore. base and analyzes the results of various reactor development scenarios on the depletion of the ore base.- The key datum in the analysis is the date at which all uranium ore is "committed." At the date of total ore commitment, there exists enough uranium to meet the need for all operating reactors through their 30-year lifetimes. In the Finite Ure Mudel, commitment means that no further converter reactors can be built. 
The Economics Model analyzes time frames in which no further uranium is available at a price below that which makes breeder reactors economical: In this model, the transition $1 /$ date is determined as the time when breeder reactors will be economically competitive with other nuclear power sys tems.

For these models, the date of transition is a function of the amount of uranium ore available, the growth of nuclear generating capacity, the relative costs of competing systems, and the efficiency with which uranium is used by thermal reactors. These variables are treated parametrically in the analysis. The efficiency of uranium utilization of thermal reactor systems forms the basis of the reactor. development scenarios which, in turn, helps define the strategies formulated.

Accordingly, the approach taken in the analysis is as follows:

o a broad set of alternative future installed nuclear capacities is postulated;

- a range of uranium resuurce estimates is assumed (f́ixpd quantity suncept) based on the best information available today (for the Finite Ore Model);

- a price-quantity uranium supply function is formulated (for $s$ the Economics Model); and

- manageable variables are introduced which relate the consumption or araniun ore to the development of alternative reactor types and enrichment tails assay, including:

1/ In Lhis paper, the breeder transition date (or breeder introduction date) is defined as the date of operation of the first commercial breeder reactor. 
- present day. LWRs,

- LWRs with improved fuel utilization,

- advanced converter reactors, and

- enrichment tails assay from $0.2 \%$ to $0.05 \%$ uranium-235.

B. Breeder Development Schedule

Two breeder development schedules are considered. An accelerated schedule is based on a 20-year time period between a demonstration breeder reactor deployment decision and the placing of commercial breeder orders which would generate $1 / 2$ quad (energy input) of electricity. A,more deliberate 30 -year schedule less subject to technological risks is also considered. (These schedules become 26 years and 36 years, respectively, to date of first breeder operation.) The major difference between the 20-year and the 30-year schedule is the addition of a commercial prototype plant of a scale similar to that which utilities would be expected to purchase. C. Strategies.

A set of four nuclear strategies are developed consistent with the range of future circumstances as forecasted and achievable with the technologies available. These strategies are designaced as:

1. Early Breeder

2. Late Breeder

3. Hedged Breeder

4. Expanded Nuclear 
Early Breeder. This strategy calls for an early commitment to the breeder. It is based on pessimistic assumptions about the uranium resource base, an expectation that the nuclear growth rate will be in the high end of "the projection range and/or that breeder economics will be competitively favorable. It is a high cost and high proliferation risk program.

Late Breeder. This strategy calls for deferral for as long as possible of the breeder and places hcavy emphasis on improvements in fucl utilization of l.WRs: It assumes an adequate resource base for many years of once-through reactor operation as well as a lower rate of gruwth of nuclear power and/or unfavorable breeder economics. This strategy has the greatest apparent non-proliferation advantages and repıesents the lowest cost program.

Hedged Breeder. This strategy is consistent with the assumption that rapid progression toward the breeder is not required but that there is sufficient uncertainty about this judgment to warrant maintaining some nptionv and flcxibility for program shifts in the event they become desirable. It is a moderate-cost program that attempts to balance investments in LWR improvement with advancing breeder technology while maintaining a strong nonproliferation stance.

Expanded Nuclear. This strategy calls for mg8reeoive programs and commitments for commercialization at the earliest realistic dates for LWRs, ACRs, and breeders. It is based on the view that nuclear will play the primary rolc in uur energy future and that the U.S. must move ahead in all technological areas. It is a very costly program with moderate proilifera-, tion risks. 
Following the development of the four'strategies, the paper discusses them in terms of conformity to our national energy goals. The discussion is formulated around the prospects of a strategy covering the largest future space of potential events. While this discussion is aimed at identifying the strategy that best conforms to satisfying our future nuclear needs, it should be emphasized that the analysis permits the interested policymaker to examine alternative strategies as desired. The analytical models are easily used for such exploration of alternatives.

\section{ANALYSIS}

A. Description of the Analytical Cases

Five different reactor systems were employed to form four analytical cases designed to span the range of future viable nuclear power systems for the U.S. These reactor systems include today's standard LWR, two improved versions of the LWR, an ACR, and a breeder reactor. The dates of introduction for the first four systems were based on technical judgments as to when the reactors would be ready for deployment. The breeder reactor introduction date was determined through the analysis based on exhaustion of committed uranium in the Finite Ore Model and based on equality of electricity production costs in the Economics Model.

The four analytical cases are: $\underline{2}$ /

Case 1: Continued installation of the current LWRs only until a transition to a breeder reactor is required. These LWRs have a 30-year 1 ifetime requirement of 550,0 tons of $\mathrm{U}_{3} \mathrm{O}_{8}$.

2/. Other combinations of these reactor concepts were analyzed. The cases are not presented because their results showed no signifieant differences from those considered here. All lifetime fue 1 requirements are based on the once through fuel cycle. 
Case 2: An improved LWR is introduced in 1985 and existing reactors are retrofitted. The improved LWR has a $15 \%$ smaller 1 ifetime ore requirement ( 4675 tons $\mathrm{U}_{3} \mathrm{O}_{8}$ ). The increased fuel efficiencies are primarily due to increased burn-up and improved fuel management. These improved LWRs are installed until the transition to a breeder reactor is required.

Case 3: An optimized LWR is introduced beginning in 2000, but reactors installed before 2000 are not retrofitted. The new LWR would have a, lifetime requircment of 42011 tone $\mathrm{U}_{3}{ }^{0} 8$, approximately $25 \%$ better than today's reactors. Between 1985 and 2000, improved LWRs are introduced. A transition to a breeder reactor is made when required.

Case 4: The improved LWR is introduced in 1985 (Case 2). In addition an ACR with lifetime requirements of 3300 tons $\mathrm{U}_{3} \mathrm{O}_{8}$ is introduced in 1995. This ACR may le any one of several advanced design nuclear systems. Again, a transition to a breedcr reactor is made when required.

B. Uranium Enrichment Tails Assay

'lhe lifetime ore requirements specified ill these cases are consistent with a plant capacity factor of $70 \%$ and the uranium enrichment facilities being operated with a $0.2 \%$ tails assay. It is quite feasible that the tails assay can be reduced to as low as $0.05 \%$ at existing or planned enrichment facilities or through advanced isotupe separation techniques that are currently under developmenl. This reduced tails assay, which can reasonably be expected to occur if the uranium price 
- rises significantly relative to the enrichment costs, lowers the lifetime ore requirements for an LWR or ACR by almost $20 \%$. Each of the four cases were also analyzed on the basis of the $0.05 \%$ tails assay being employed in the mid-1990's (stockpiled depleted uranium would also be "stripped" to the lower tails assay).

C. Range of Nuclear Power Growth

The projected growth in nuclear energy demand is crucial to the deve1opment of a sound strategy. The historical uncertainties in such projections warn us that a sound strategy must be flexible and maintain reasonable options to maximize chances of success. In order to incorporate this uncertainty, the analysis includes nuclear projections of $200 \mathrm{GWe}, 300 \mathrm{GWe}$, and 400 GWe installed capacity by the year 2000. Because the nuclear growth pattern beyond 2000 is even more speculative, the analysis includes annual reactor additions of $10 \mathrm{GWe}, 15 \mathrm{GWe}$, and $20 \mathrm{GWe}$, for an indefinite number of years so that resource exhaustion and economic competition can be examined.

\section{Uranium Resource Estimates}

The best current official estimates of the amount of uranium resources available at cost of $\$ 50 / 1 b$. classified according to the present means of reporting these resources are shown in Table 3 . Because of the variations in opinion that exist todáy about the available resources, a range of estimates has been used in this analyois:

For the Finite Ore Model, values of $1.8,3.6$, and 4.5 million tons of $\mathrm{U}_{3} \mathrm{O}_{8}$ have been chosen. The lower value is representative of the CONAES findings and is approximately equal to pre-NURE estimates of reserves plus 
TABLE 3

BEST CURRENT NURE ESTIMATE

OF THOUSANDS OF TONE YETTIOW CAK.E $\left(U_{3} O_{8}\right)$

4.

Forward Cost

Less Than $\$ 50 / 1 \mathrm{~b}$.

Reserves

890

Probable Resources.

1,395

Possible Resources

1,515

Speculative Resources

565

Total

$\underline{4,365}$ 
probable resources. The higher value is approximately equal to the current NURE estimates of uranium resources in the U.S. below $\$ 50 / 1 \mathrm{~b}$. forward cost.

Uranium resources are more likely to be available in a manner similar to oil, gas, or other mineral resources. In those situations, larger quantities are available at higher costs thus generating a price-quantity supply curve of resources.

In the Economics Model, a $\mathrm{U}_{3} \mathrm{O}_{8}$ supply curve, estimated by the DOE Division of Uranium Resources and Enrichment and used in the Non-Proliferation Alternative Systems Assessment Program (NASAP) study, has been adopted for this analysis (Figure 1). This figure shows the marginal cost of $\mathrm{U}_{3} \mathrm{O}_{8}$ as a function of cumulative supply for two supply assumptions, identified as intermediate-cost and high-cost. The price of $\mathrm{U}_{3} \mathrm{O}_{8}$ in any year in this analysis, for computing the economic crossover to a new reactor system, is determined by the marginal cost of the next uncommitted pound of $\mathrm{U}_{3} \mathrm{O}_{8}$ in that year (based on tracking up the supply curve for previous ore commitments). The effect of using an advanced enrichment process to re-enrich the uranium calls is sliown with broken lines. The advanced process is assumed to supply feed to enrichment plants ("mining" the tails stockpile) at an equivalent price of $\$ 43 / 1 \mathrm{~b}$. of $\mathrm{U}_{3} \mathrm{O}_{8}$. E. Cost Comparisons of Alternative Reactors and Fuel Cycles

The Finite Ore Model does not make use of the relative costs of an alternative reactor system. However, the Economics Model is sensitive to relative cost assumptions. For this analysis, the NASAP data base on relative. costs has been used (Table 4 ). 
Figure 1

\section{$\mathrm{U}_{3} \mathrm{O}_{8}$ Marginal Cost for High and intermediate Price $\mathrm{U}_{3} \mathrm{O}_{8}$ Supply Curves}

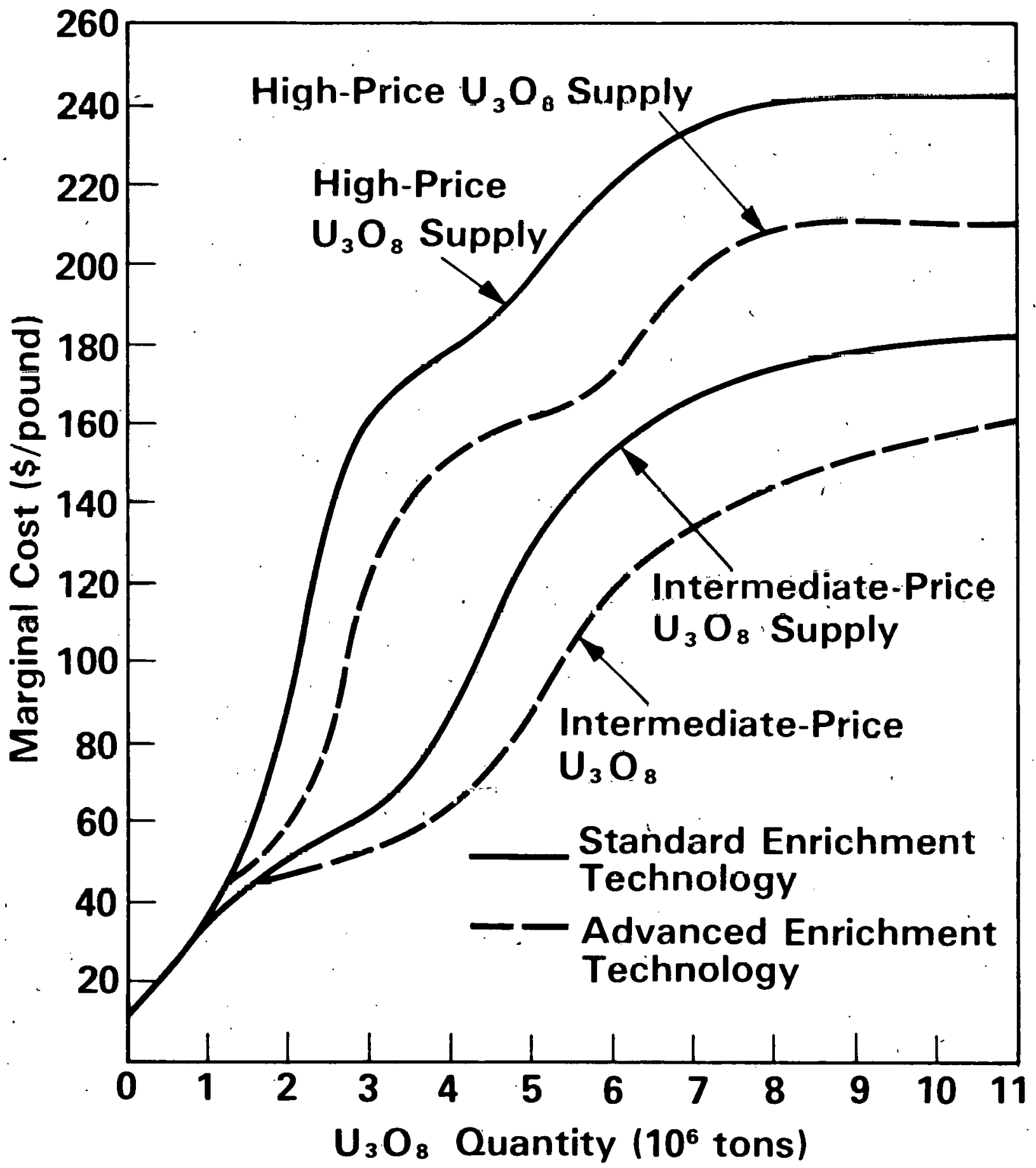


TABLE 4

ECONOMIC DATA $^{(*)}$

Capital Costs (including owner's cost and IDC)

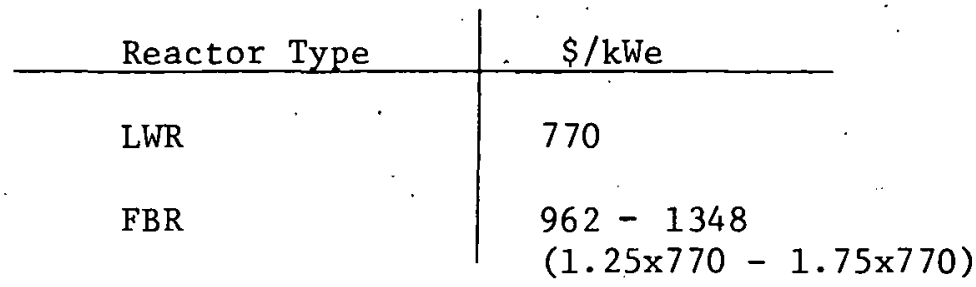

Operation and Maintenance Costs

\begin{tabular}{c|c|c} 
Reactor Type & Fixed $(\$ / \mathrm{kWe}-\mathrm{yr})$ & Variable $(\$ / \mathrm{kWe}-\mathrm{yr})$ \\
\hline \multirow{2}{*}{ LWR } & 11.2 & 0.5 \\
FBR & 11.7 & 0.9
\end{tabular}

Fabriçation Costs

\begin{tabular}{l|c} 
Reactor/Fuel Type & $\$ / \mathrm{kg} \mathrm{HM}$ \\
\hline LWR & 115 \\
FBR -Pu/U Oxide & $1500 * *$ \\
$\quad$ ThO 2 Radial Blanket & 160
\end{tabular}

\begin{tabular}{l|c}
\multicolumn{2}{c}{ Reprocessing Costs } \\
Reactor/Fuel Type & $\$ / \mathrm{kg}$ HM \\
\hline LWR - Throwaway & 150 \\
FBR - (U,PU) $0_{2}$ & 560 \\
$(\mathrm{U}, \mathrm{Th}) \mathrm{O}_{2}$ & 570
\end{tabular}

Enrichment Cost

$100 \$ /$ SWU

* Extracted from NASAP data base.

** Fabrication cost of assembly divided by number. of kilograms $\overline{\text { in }}$ active core region for that assembly. 
The most important cost element is the capital costs of different nuclear units (in 1977 , the capital costs were $77 \%$ of the total generating costs of nuclear plants). Initial cost evaluations indicate that the improved LWR and optimized LWR would not significantly differ from costs of a standard LWR. However, two independent studies are in progress to give better estimates on potential cost differentials. The brepder reactor capital costs range from $25 \%$ to $75 \%$ greater than the reference LWR.

The second most important cost element is the uranium fuel cost. The rising fuel costs for LWRs and ACRs are based on the uranium supply curves in Figure 1. When these costs rise suffiriently to offset the capital cost advantage held over hreeder rcactors, then the model chooses the breeder.reactor for the next year's nuclear installations. These rising uranium costs also affect the indifference value (implicit $\cos 5$ ) of plutonium or thorium.

F. Results of the Finite Ore Model Calrulatione

The Finite Orp Madel calculatiuss were designed to show the last year that a standard LWR could be installed and to show the extensions of thal date that could be achieved through introduction of an improved LWR, an optimized LWR, or an ACR. These dates reprcaent the last year that an LWR or ACR could be installed and still have sufficient uranium to fuel the reactora for their lifetime ( 30 years), assuming no additional uranium ore is discovered and no recycle of uranium. These results are given in Tables 5 and 6.

The dates shown in these Tables are not precisely the dates in which the first breeder reactor must become operational if the breeder is to replace converter reactors in a gradually phased-in manner. How- 
TABLE 5

DATE OF TOTAL $\mathrm{U}_{3} \mathrm{O}_{8}$ COMMITMENT

(0.2 Tails - Once Through)

Uranium Ore Base (Millions of Short Tons of $\mathrm{U}_{3} 08$ )

\begin{tabular}{llllllll}
\hline \multicolumn{2}{l}{1.8} & & $\frac{3.6}{15}$ & & $\frac{4.5}{10}$ & 15 & 20
\end{tabular}

Growth Rate (GWe/yr):

$\begin{array}{lllllllll}2008 & 2006 & 2005 & 2028 & 2021 & 2017 & 2035 & 2029 & 2023\end{array}$

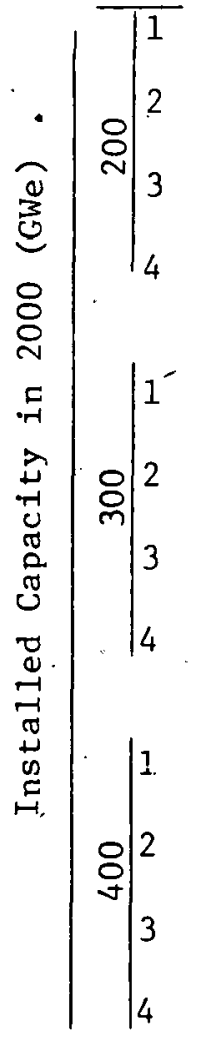

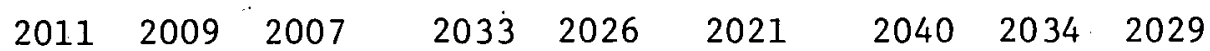

$\begin{array}{lllllllll}2012 & 2010 & 2008 & 2035 & 2030 & 2024 & 2043 & 2036 & 2031\end{array}$

$201520112009 \quad 2041 \quad 2034 \quad 2030 \quad 2052 \quad 2042 \quad 2036$

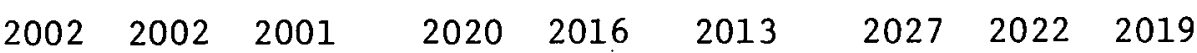

$\begin{array}{lllllllll}2005 & 2004 & 2004 & 2024 & 2020 & 2017 & 2033 & 2027 & 2023\end{array}$

$\begin{array}{lllllllll}2006 & 2005 & 2004 & 2027 & 2022 & 2019 & 2035 & 2030 & 2025\end{array}$

$\begin{array}{lllllllll}2007 & 2005 & 2004 & 2033 & 2027 & 2022 & 2042 & 2035 & 2031\end{array}$

$\begin{array}{lllllllll}1997 & 1997 & 1997 & 2015 & 2012 & 2010 & 2021 & 2018 & 2016\end{array}$

$\begin{array}{lllllllll}1999 & 1999 & 1999 & 2019 & 2016 & 2014 & 2026 & 2022 & 2019\end{array}$

$\begin{array}{lllllllll}1999 & 1999 & 1999 & 2020 & 2018 & 2015 & 2028 & 2024 & 2021\end{array}$

$\begin{array}{lllllll}2000 \quad 2000 & 2000 \quad 2024 & 2020 \quad 2018 & 2034 & 2028 & 2025\end{array}$

Case 1: LWR (5500 tons). only

Case 2: T.WR (5500 tons) to 1985 - Then all convert to improved.. LWR (4675 tons)

Case 3: Case 2 and optimized LWR (4200 tons) for all after Year 2000

Case 4: Case 2 and ACR (3300 tons) introduction in 1995 
TABLE 6

DATE OF TOTAL $\mathrm{U}_{3} \mathrm{O}_{8}$ COMMITMENT

$$
\text { (.05\% Tails - Once Through) }
$$

Uranium Ore Base (Millions of Short Tons nf $\mathrm{Y}, 08$ )

\begin{tabular}{|c|c|c|c|c|c|c|c|c|c|c|c|}
\hline \multirow[b]{2}{*}{ Growth } & \multirow{2}{*}{\multicolumn{2}{|c|}{$\begin{array}{r}\text { Rate (GWe/yr): } \\
\text { CASE }\end{array}$}} & \multicolumn{3}{|c|}{1.8} & \multicolumn{3}{|c|}{3.6} & \multicolumn{3}{|c|}{4.5} \\
\hline & & & 10 & 15 & 20 & 10 & 15 & 20 & 10 & 15 & 20 \\
\hline & & 1 & 2012 & 2010 & 2008 & 2035 & 2029 & 2023 & 2042 & 2035 & 2031 \\
\hline & & $0^{2}$ & 2016 & 2013 & 2010 & 2040 & 2033 & 2028 & 2048 & 2039 & 2034 \\
\hline & 3 & 3 & 2018 & 2014 & 2012 & 20.43 & 2035 & 2031 & 2052 & 2042 & 2037 \\
\hline & $\stackrel{\complement}{\complement}$ & 4 & 2020 & 2015 & 2012 & 2046 & 2038 & 2033 & 2058 & 2046 & 2039 \\
\hline &.$F$ & 1 & 2007 & 2005 & 2004 & 2026 & 2022 & 2018 & 2035 & 2029 & 2025 \\
\hline & $\sum_{0}^{2}$ & $\stackrel{\mathrm{m}}{2}^{2}$ & 2010 & 2008 & 2007 & 2032 & 2027 & 2023 & 2041 & 2034 & 2030 \\
\hline & $\frac{2}{3}$ & 3 & 2011 & 2009 & 2008 & 2035 & 2029 & 2025 & 2044 & 2037 & 2032 \\
\hline & تِ & 1/1 & 2013 & 2010 & 2008 & 2038 & 2032 & 2027. & 2048 & 2040 & 2035 \\
\hline & $\underset{\Xi}{\stackrel{\Delta}{心}}$ & 1 & 2001. & 2001 & 2001 & 2020 & 2018 & 2015 & 2027 & 2023 & 2021 \\
\hline & & 워 & 2005 & 2004 & 2003 & 2025 & 2022 & 2019 & $203 / 1$ & 2029 & 2025 \\
\hline & & 3 & 2005 & 2004 & 2003 & 2027 & 2023 & 2021 & 2037 & 2031 & 2027 \\
\hline & & 14 & 2006 & 2004 & 2003 & 2030 & 2025 & 2022 & 2041 & 2034 & 2030 \\
\hline
\end{tabular}

Crase 1: LWR (4450 tons) only.

Case 2: LWR (4450 tons) to 1985 - Then all convert to improved LWR (3795 tuns)

Casc 3: . Case 2 and optimized LWR ( 3400 tons) for all after year 2000

Cașe 4: Case 2 and ACR (3030 tons) introduclion 1n 1995 
ever, the dates in these Tables are extremely close (within one to three years) to the dates of a first breeder operation and, thérefore, can be used as a very good approximation of breeder introduction dates.

The adjustment, to the dates in Tables 5 and 6 that are necessary to show the date of first breeder operation are given in Appendix A. The adjustments include: 1) the recycle of $U-235$ in the converter reactors resulting from fuel reprocessing facilities that would have to be constructed if breeder introduction were imminent; and 2) the phasing-in of breeder reactors and phasing-out of converter reactors so that a normal penetration rate is established for the breeder reactors which would permit'breeder reactors to satisfy all market demand for new and replacement nuclear power by the last year that a converter reactor can be installed.

The tables may be summarized as follows:

- Low Ore Base. If the ore base is only 1.8 million tons, breeder reactors must be introduced around the year 2000 .

- Medium Ore Base. If the ore base is $3.6 \mathrm{million}$ tons, several choices are available.

- with only deployment of standard LWR, breeder reactor introduction can be delayed until some time between 2010-2030, the variation depending principally upon the post-2000 nuclear installation rate;

- LWR improvements would, inter a'lia, del'ay breeder introduction a further 5 to 7 years; 
- initial improvements in LWR fuel utilization (15\%)

followed by introduction of an ACR in 1995 would delay breeder introduction an additional 3 to 5 years beyond that achieved by LWR improvements only

For the situations above, tails stripping to $0.05 \% \mathrm{U}-235$ would effectively add another 6 to 8 years on non-breeder nuclear capacity to the ore base. With an improved once-through fuel cycle and uranium tails stripping,. the uiedium ore base would not be exhausted until around 2025-2050, the range depending on assumed nuclear power growth rates.

- Large Ore Base. For an ore base of $4.5 \mathrm{million}$ tons, the following choices are available:

- breeder introduction between 2015 and 2035 if only currenL LWRs are deployed;

- LWR improvement would delay breeder introduction by an äditional 5 Lu 8 yeárs;

- significant improvements in LWRs or introduction of ACRs, would not require brccder illroduction before 2030 and, perhaps, later than 2050.

Tails stripping to $0.05 \% \mathrm{U}=235$ for the large ore base would also add 6 to 8 years to the available ore base. - With an iuproved once-through. fuel. cycle -. and uranium tails stripping, the high ore base would not be exhausted until around 2030, even assuming high demand projections. For lower demand projections, breeders would_not be necessary until after 2050. 
From the tables and summary, several important conclusions can be drawn:

- Under the assumptions of high installed nuclear capacity (400 GWe), a low ore base ( 1.8 million tons), and little or no LWR improvements, the date of; ore exhaustion is no earlier that 1997. The intermediate ore base adds from 13 to 17 years to the exhaustion date and the higher ore base would not exhaust supplies until around 2020. Tails stripping adds another 4 to 6 years of effective supply.

o Not surprisingly, the low ore base shows that improvements in LWRs or a transition to ACRs does not prolong the breeder introduction date. Under this case, the ore resources are exhausted beforé significant non-breeder improvements can be effected.

o The introduction of both the Improved and optimized LWR shows marked effects for all but the low ore base case. LWR improvements for the intermediate and high ore resource casco add frnm 5 to 8 years of additional generating capacity

o Modest improvements in the LWR followed by the introduction of ACRs around 1995 would stretch the committed ore exhaustion date for intermediate and high resource bases from 8 years to more than 15 years when compared to the use of unimproved LWRs. 
- The earlier the improved LWR or the ACR is introduced, and the larger the ore base, the greater the contribution in extending the lifetime of the once-through LWR system. Additional advantages accrue for low reactor ore requirements such as reduced mining, reduced environmental problems from mill tailings, reduced spent fuel and storage requirements.

\section{G. Results of the Economics Model Calculations}

The results of the Economics Model calculations $\frac{3 /}{}$ are given in Appendix A. A representative sample of these calculations is given in Table.7. The years in the tables represent the year in which the breeder reactor would become economically competitive with the LWR in an operational mode. Therefore, orders for breeder reactors presumably would be placed several years earlier. Following the transition date, breeder reactors would be phased-in on a nurmal penetration pattern until they could account for all new plus replacement plants. During this phase-in period, cunvercer reactors would onntinuc to be illecalled in a phasing-out manner. The following obscrvations can be made from the analysis:

- For a breeder reactor with capital costs 1.75 times an LWR, thcre is vircualiy no set of assumptions about uranium supply or nuclear growth that would Teàd to an economic transition to the breeder be före-_2025:

$3 /$ Due to the current-structure of the Economics Model, it was not possible to analyze the ACR introduction (Case 4) in the manner prescribed for the case. Although these results have been omitted from Lhis paper, it is suspected that they would look similar to the "results" from the Finite Ore Model. 
TABLE 7

Installed Capacity. In 2000 (GWe):

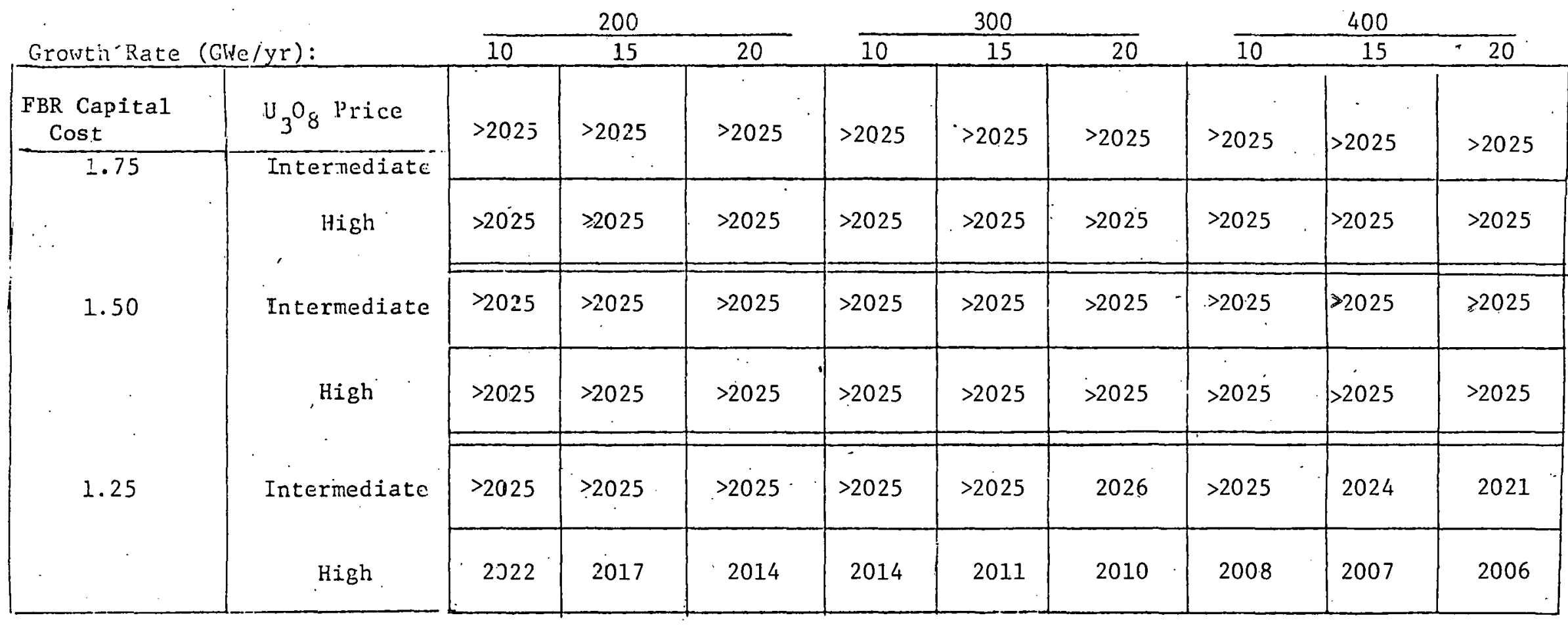

Date of Economic Transition to the FBR.from the LWR with $25 \%$ Improvement

in $\mathrm{U}_{3} \mathrm{O}_{8}$ Utilization on the Once-Through Cycle with $0.2 \%$ Tails 
- For a breeder reactor with capital costs 1.50 times an LWR:

- there would be no economic transition to a breeder before 2025 with the intermediate uranium price and most any nuclear growth pattern;

- with the high uranium price, an economic transition to the breeder between 2000 and $2025^{\prime}$ would occur when compared to an unimproved LWK, between 2010 and post-2025 when compared to a $15 \%$ improved fucl ntilisatiun LWK, and post-2025 when an additional $10 \%$ fue 1 utilization is incorporated in LWRs $i_{11}$ 2000

- For a breeder reactor with capital costs 1.25 times an LWR, an economic transition would occur before 2025 for most combinationn ef usguiutions concerning uranium supply and nuclear growth for both the unimproved. LWR and the $15 \%$ improved fuel utilizatinn LWR: However, if the full $25 \%$ improvements in LWRs occur, the economic transition is beyond 2020 for all cases with an interutedlate uraniım prire.

$\because \quad 0$ The $15 \%$ improvement in uranium utilization of the standard LWR can delay the ernnomic tianoition to the breeder between five and ten years.

- The additional $10 \%$ improvement in optimized LWRs introduced in 2000 adds an additional three to ten years to the transition. 
- Compared to the analysis which used presently available enrichment with $0.2 \%$ tails, an improved enrichment process with $0.05 \%$ tails should extend the economic transition date to the breeder by three to seven years for any type of LWR. Use of a 15\%-improved, high-burnup LWR adds some five to eight years to the transition date and use of a $25 \%$-improved optimized LWR adds an additional three to four years.

- The use of lower tails assay for uranium enrichment leads to the following observations:

- For a high capital cost breeder with any nuclear growth or $\mathrm{U}_{3} \mathrm{O}_{8}$ supply or an intermediate cost breeder with an intermediate price $\mathrm{U}_{3} \mathrm{O}_{8}$ supply, transition from any type of LWR to the breeder is not economical prior to 2025.

- For an intermediate capital cost breeder with a high price $\mathrm{U}_{3} \mathrm{O}_{8}$ supply or a low cost breeder with an intermediate price $\mathrm{U}_{3} \mathrm{O}_{8}$ supply, transition to the breeder before 2025 would probably occur only if standard LWRs were still the predominant type in use. In this case, the economic transition date is strongly dependent on the assumed nuclear energy demand.

- For a low capital cost breeder with a high price $\mathrm{U}_{3} \mathrm{O}_{8}$ supply, transition to the bieeder from all types of LWRs considered is generally economical between 2000 and 2025 with the exact year dependent on the nuclear energy dewand assumed. 
H. Analysis of Other Factors

other factors which are to be considered are:

- Environmental

- Safety

- Non-Proliferation

o Thorium Fuels.

\section{Environmental}

The deployment of nuclear reactors of any type, much like any energy techuology, results in some form of insults to the environment. All of the reactor and fuel cycle development programs are designed lo reducc these impacts to meet current and future environmental standards. In this strategy paper, the focus is toward the significant differences in environmental impact resulting from the deployment of alternative types of reactors rather than a discussion of impacts common to the use of any type of nuclear power.

A major diffcrence among the deplnyment of diffeient types of reactors is the total requirements for uranium mining and milling, $a^{\text {. }}$ segment of the fuel cycle industry that typically hao the largest environmental impact. The mining and milling requirements per unil of energy are reduced the most with a breeder. The ACR and the improved i LWRs also reduce these requirements relative to the continued use of the standard LWR.

The major increased environmental impact of either the breeder or the ACR fuel cycle is the need for Purex and/or Thorex reprocessing. In addition, if Thorex is employed, there will be an impact from the required thorium mining and milling industry. 
The thermal impact and cooling water requirements are significantly lessened by either a breeder or ACR. This change is based on the projected higher thermal efficiency characteristics for these types of reactors relative to the LWR.

The impacts of low-level radiation from plant operations and impacts resulting from nuclear waste management activities are probably small differences among all types of reactors. $\underline{\text { Safety }}$

The introduction of any new system will require additional confirmatory safety $R \& D$ and regulatory action before licensing. In general, ACRs, being fairly similar in many aspects to present operating systems, may introduce less problems of a safety assessment nature than breeders. The introduction of Heavy Water Reactors (HWR) of the CANDU type into the U.S. would, however, require considerable safety study based on U.S. regulations and criteria. Non-Proliferation

The current operational fuel cycle in. the U.S. and most of the world is the LWR once-through cycle (and, to a much smaller degree, the HWR). The once-through fuel cycle consists of reactors using.. natural or low-enriched fuel only once (no reprocessing), with a limited number of enrichment facilities contained within the context of nuclear weapons states or in the institutional context of bilateral agreements; the Non-Prolifcration Treaty and International Atomic Energy Agency safeguards. The most significant characteristic of the once-through nuclear power system is that no material exists 
that is directly weapons-usable in any part of the fuel cycle. Further, the materials are relatively difficult to convert to such forms, and facilities for plutonium recovery and conversion are not necessary. The once-through fue 1 cycle is today generally referred-to as the reference, or benchmark case, from a proliferation resistance point of view, since its inherent resistance to proliferation pathways is greater than other envisioned systems.

The breeder and (thermal) recycle fuel cycles include facilities for plutonium recovery, storage, fabricalion, and shipment. Plutonium inventories would be very high: thousands of kilograms at reprocessing plants and hundreds of thousands of kilograms in national or international commerce. Proliferation resistance of breeders or plutonium recycle would be very low compared to once-through fuel cycles. Even if processes were developed which could keep the fuel cycle material in a form that is not directly usable in nuclear explosives, the presence of the facilities would provide a base for national conversion of these materials, a source of training and experience for personnel, and an excellent cover for undeclared facilities.

During the past sevicral, years, there has been increasing attention in the international community to the potential for spread to additional. states of a uuclear weapons capability. The Uss.-intiated International Nuclear Fuel Cycle Evaluation (INFCE) has played an important role in this activity. With a large body of international attention focused on non-proliferation, the U.S. nuclear RD\&D program and strategy for the future must be sensitive to this issue. 
Thorium Fuels

Thorium fuels for nuclear power have not been considered in this analysis. Thorium fuels offer an entirely. new resource base for nuclear,power with a potential fully as great as that of uranium. However, a substantial amount of development work is needed before thorium can begin to fulfill this potential.

Thorium, as a substitute fertile nuclear material for $\mathrm{U}-238$, has interesting advantages, both from a resource efficiency and-a nonproliferation perspective. Thorium can only be utilized if it is incorporated in breeders or converters since thorium itself is not fissile. The U-233 produced from thorium is a far more efficient fuel in a thermal spectrum that either U-235 or Pu. This fact manifests itself most clearly in strategies that consider a "closed system" of fast breeders supplying fuel for thermal converters.

Thorium fuel has desirable non-proliferation advantages. The most significant is that it permits the deployment of the so-called denatured thorium-uranium fuel cycle wherein the $\mathrm{U}-233$ can be isotopically diluted with U-238 to be used a safe "exportable fuel" for converter reactors.

The DOE NASAP program is considering application of thorium fuels. These results are being factored in to the INFCE proceedings. These studies should be encouraged and the results carefully analyzed for program direction. 


\section{Breeder Development Schedule}

Prototypical breeder deployment schedules of 20 and 30 years are represented in Figures 2 and 3 . These schedules begin with a decision to seek the necessary commitment to construct a demonstration plant. This decision date is after the completion of a conceptual design study which establishes the actual size and technical configuration of the reactor. The time schedules continue through the construction and operation of a demonstration reactor in the 20-year strategy or a demonstration reactor and commerial protorype in the 30-yedr serategy.

Assuming that breeder economics and technology continue to be favorable, the end of the process would be a technology that is fully deployable in the sense that an electric utility could order a breeder reactor with the same confidence that it would have in selecting alternative generating plants. For these time srhodulno; it it usumed that this point is reached when breeder plants sufficient to produce $1 / 2$ quad of electric cnergy (appruximately eight plants) have been ordered. USing a nominal 10-yeds lead time from date of order to date of operation of the reactor, the 20-year or 30-year time schedule is completed four years after the initial breeder order or six years before the initial breeder operation. If one used the date of first breeder operatinn 28 thc cnd puint for these schedules, then these deployment schedules would be 26 years or 36 yeara in lumgth of time..

The 20-year schedule represents an accelerated deployment strategy. It assumes that utilities..will be prepared to order large (1000-1400 MWe) breeder plants at a time in which only limited operating experience is 


\section{Year Case FBR Strategy}

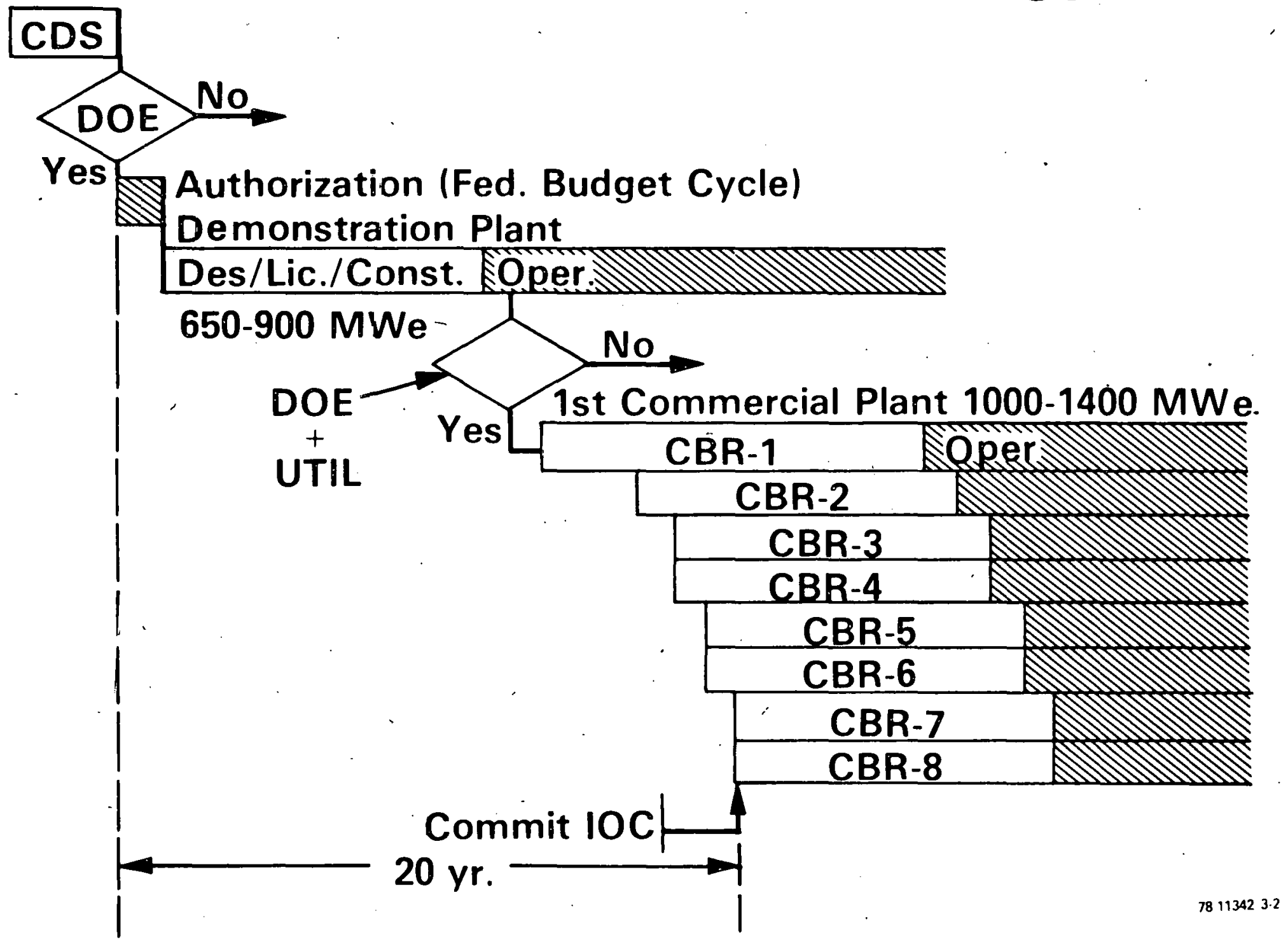




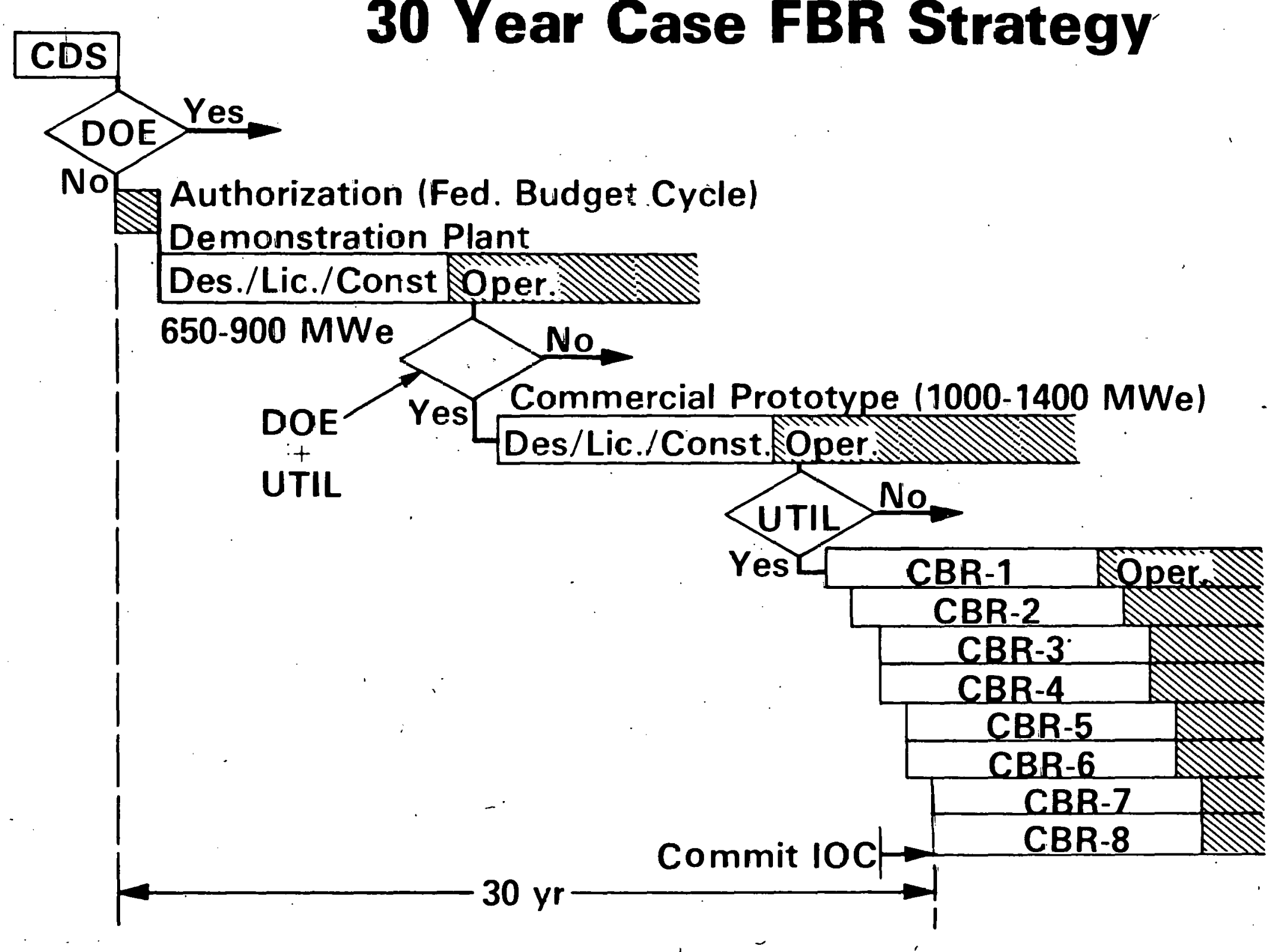

\section{Year Case FBR Strategy}


available from a smaller (600-900 MWe) demonstration plant. For this to be true, the construction and early operation of the demonstration plant must proceed more smoothly than has been'the case with previous nuclear enterprises.

The 30-year schedule represents a more deliberate pace which is less subject to technological risks. The principal difference from the 20-year schedule is the addition of a commercial prototype plant of a scale similar to that which,utilities would be expected to purchase. Thus, the utility decision-maker would be able to order a breeder on the basis of. extensive operating experience with a small demonstration plant and limited operating experience with a ful1-scale plant. J. How the Policy-Maker Uses the Analysis

The analysis has been prepared to capture a range of views and uncertainties relating to the most sensitive parameters affecting future nuclear power development. The policy-maker may use the analysis to select the combination of values that he deems most appropriate. By this process, one can make judgements on the timing for decisions on moving to the next etages of RD\&D for various nuclear programs.

Either the Finite Ore Model or the Economics Model is chosen. Values for the uranium enrichment tails assay, the uranium ore supply, the nuclear power projections for the year 2000, the nuclear growth rate in the post-2000 period, and the relative capital costs of reactors (if the Economics Model is chosen) are selected. A selection of an LWR or ACR development and deployment scheme is made. From these choices, one can find the year of breeder transition from the data tables. Using one of 
the two deployment schedules for breeder development, one can then determine at what date the commitment to a breeder demonstration plant would be advisable.

As an example of this process, the following choices are illustrative parameter selections:

Model :

Tails Assay

Uranium Supply:

- Relative Capital Cost:

Nuclear Projection (2000):

Nuclear Growth (post-2000):

LWR/ACR Deployment:

Breeder Deployment Schedule:
Economics Model

$0.2 \% \quad U-235$

Intermediate Cost Curve

Breeder is 1.23 times LWR

300 GWe

$20 \mathrm{GWe} /$ year

Optimized LWR in 2000 (Case 3)

Using Table 7, which displays the results for Case 3 in the Economics Model, the year 2026 is the economic transition point for the first breeder. Using Figure 3, the first operational breeder is 6 ycars beyond the cumpletion of the 30-year breeder development scheme. Thus, the date of commitment to a breeder demonstration facility would ut have' to take place until 1990. If commitment took place in 1990, a 30-year development schedule to commercializatiun could be pursued, and the breeder reactor could be deployed in sufficient time co meet the projected ernnomic transition date.

An important point should be made about the consequences of not precisely meeting the breeder transition dates. If the breeder is available later than the projected transition date, the result is not a collapse of 
the nuclear system. Several types of adjustments could be made during the period required to rebalance the system. For example, there could be a pause in the assumed constant addition rate to nuclear capacity. Also, one could "borrow" from the ore base committed to the LWR inventory to build additional LWRs and pay back with mixed oxide fuel later when breeder production has come on line.

\section{ALTERNATIVE NUCLEAR STRATEGIES}

A set of alternative nuclear strategies has been examined that is consistent with a range of futures representative of differing views on how nuclear energy demands may be met. These alternative strategies set forth statements about Federal actions for each generic technology within the fission program. The strategies are oriented towards bringing the technology to a defined market or state of technical readiness at some defined future date in a manner that satisfies the criteria of economics, resource use, proliferation and environmental concerns.

The strategies are hased on types of nuclear reactors as the main thrust.' The supporting fuel cycle work is a derivative of the mainline reactor prograll. The nuclear waste management component of the strategy is independent of the reactor strategy because it is absolutely essential that progress be made in this area in order to remove a large element of uncertainty in the nuclear energy program. The R\&D funding strategies are expressed in terms of the Research, Development, and Commercialization (RD\&C) classification adopted for the DOE Program and Project Management System (PPMS). A summary of the relative program emphasis for each strategy is presented at the end of this section in Table 8 . 


\section{A. Strategies}

\section{Strategy 1: Early Breeder}

This strategy is consistent with the view that the uranium resource base is limited, that the nuclear growth rate will be in the high end of the projection range, and/or that breeder economics will be competitively favorable. This view would argue that an early commitment must be made to the breeder reactor.

A proposed DOE strategy for this nuclear future is:

Breeder Technology

LMFBR :

Commit to funding LMFBR through the Commercializalion stage. Complete the Conceptual Design Study by 1981 and

$$
\text { commit to a Demonstration facility by }
$$$$
\text { 1982. Initiate planning to hring the }
$$$$
\text { breeder to a stage of commercial }
$$$$
\text { deployment in } 20 \text { years. }
$$

Alternative Breeders: Provide some increase in GCBR programs to serve as a hedge against LMFRR. problems.

Reprocessing:

Fund R.D on ieprocessing for breeder fuel, as an accelerated program, through the Commercialization stage.

\section{Alternative Reactor Technologies}

LWR Improvements:
Provide some market incentives and analytical support to Improved LWR to stretch uranium resources until breeder 
commercialization. As a hedge, fund

R\&D on Optimized LWR through the

Engineering Development stage.

ACR Development:

Initiate planning for an ACR program

that can be complementary to a breeder

world in post-2000, with a decision

point on a-serious funding effort to

be made within 5 years.

Resources and Enrichment

AIST:

Reduce AIST program to one process,

funded through the Exploratory

Development stage, but with no near-

term decision date on proceeding to

Technology Development'stage.

NURE :

Reduce emphasis on NURE program,

allowing for a stretchout of currently

planned program.

Centrifuge Facility: Construct Centrifuge Facility on present schedule (because this visw nf the future has potentially high nuclear growth). Initiate planning on new enrichment facilities, with some hedge planning towards tails stripping.

Waste Management

Commercial Wastes: Proceed at rapid pace to carry out IRG recommendations on Waste Management. 


\section{Strategy 2: Late Breeder}

This strategy is consistent with the view that the uranium resource base, is sufficient for many years of once-through reactor operation; that the nuclear growth rate will be towards the lower end of the projections, and/or that breeder econoaics will remain unfavorable. This view would argie that the breeder should be deferred for as long as possible and that heavy emphasis should be placed on improvements in fuel utilization of LWRs and introduction of ACRs.

A propused DOE strategy for this nurlear fulure is:

Breeder Technology

LMFBR :

Réduce funding for LMFBR to Technology and Engineering Development on a stretchedout program. Delay decision point for Demonstration conuilment until the $1990^{\prime} \mathrm{s}$.

Alternative Breeders: Terninate the GCBR program.

Reprocessing: Terminate programs on somnoceial réplucesing or engage only in international collaborative programs for nun-proliferation objectives, Furid Applied Research R\&D on advanced methods.

\section{Mlternative Reactor Terhnologies}

LWR Luprovements: Provide market incentives and supporting R\&D for Improved LWR to obtain retrofit of cxisling reactors by 1985. Fund R\&D on Optimized LWR through the Commercialization stage, to be achieved by 1988 . 
ACR Development: Fund R\&D on ACR to complete Technology Development stage. Initiate early plan- ' ning to establish basis for strategy decision on more aggressive development program.

Resources and Enrichment

AIST:

Fund R\&D in the'Exploratory Development stage for three processes. Decision point in 1982 on proceeding to Technology Development stage.

NURE : Continue high emphasis on NURE program with more emphasis on drilling to improve resource estimates.

Centrifuge Facility: Initiate planning for methods and cost evaluations of tails stripping from existing and pianned facilities. Alter pace of Centrifuge Facility to match projected market demands.

Waste Management

Commercial Wastes:- Proceed at rapid pace to carry out the IRG recommendations on Waste Management.

Strategy 3: Hedged Breeder.

This strategy is consietent with a view that the resource base, nuclear growth, and breeder economics can be reasonably judged to have values that do not require rapid progression to the breeder. However, the strategy recognizes that there is substantial uncertainty about this 
judgement. It maintains some options and flexibility at a reasonable level of activity so that shifts in programs are relatively easy to make if future information changes that judgement.

A proposed DOE strategy for this nuclear future is:

Breeder Technology

LMFBR :

Fund LMFBR component testing, safety

evaluation and fuel evaluation programs

through Engineering Development stage.

Complete Conceptual. Design Study bỹ 1981 .

Decision point for Breeder Demonstration

to be cunsidered in 1981 but could be

deferred to 1986-1990. Initiate planning

for both a 20-year and 30-year deploy-

ment program.

Alternative Breeders: Continue modest $R \& D$ funding program for the GCBR with work focused in the Technology Development stage.

Reprocessing: Continue to delay action on rommercial repronessing. Pruvide funding for Teclunulogy Development stage.

\section{Alternative Reactor Technologies}

LWR Improvements: $\quad$ Provide market incentives and supporting

R\&D for Improved LWR to obtain retrofit of existing reactors by 1985 . Fund R\&D on Optimized LWR through the Commercialization stage, to be achieved by 1988 . 
ACR Development:

Fund R\&D on ACR to complete Technology

Development stage with more focus on common technology to all ACRs. Decision point to move to Engineering Development stage to be reevaluated in about five years.

Resources and Enrichment

AIST:

NURE :

Centrifuge Facility:

Fund R\&D in Exploratory Development stage for three processes. Decision point in 1982 on whether to proceed to Technology Development stage.

Continue high emphasis on NURE program. to ensure completion by 1985. .

Initiate planning for methods and cost evaluations of tails stripping from existing and planned facilities. Alter pace of Centrifuge Facility to match projected market demands.

\section{Waste Management}

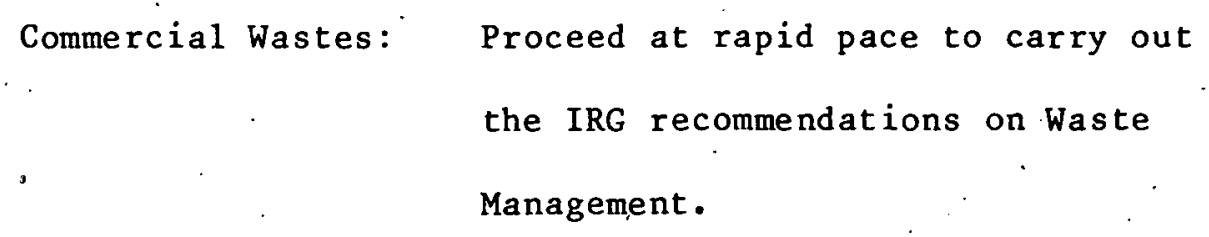

Strategy 4: Expanded Nuclear

This strategy is consistent with the view that nuclear will play the primary role in our energy future, with installed capacity possibly greater than the high projection used in this analysis, and 
that the U.S. must move ahead rapidly in all technological areas. This view would argue for aggressive programs in LWRs, ACRs, and breeders with commitments to commercialize at the earliest realistic dates.

A proposed DOE strategy for this nuclear future is:

\section{Breeder Technology}

LMFBR :

Fund the LMFRR through the Commercialization stage. Complete the Conceptual, Design Study by 1981 and commit to a Demonstration facility by 1982. Initiate planning for both a 20-year and 30"year deployment schedule.

Alternative Breeders: Provide some increase in GCBR programs to serve as hedge against LMFBR problems.

Reprocessing: , Fund R\&D on reprocessing for breeder fuel, as an accelerated program, through the Commercialization stage.

\section{Alternative Reactor Technologies}

LWR Improvements: Provide supporting R\&D for the Improved LWR... Fund the Op.timized fiWR through Llie Engimerring Development. stage with a decision point on Demonstration stage to occur in about five years. 
ACR Development: $\quad$ Fund R\&D on ACRs through the Engineering Development stage with decision point on a Demonstration facility to be made in a few years:

Resources and Enrichment

AIST:

Fund R\&D in the Exploratory Development stage for three processes with a decision point in 1982 on proceeding to Technology Development stage.

NURE : Moderate emphasis on NURE program, with some stretch-out of program, to give bettér resource estimates.

Centrifuge Facility: Construct Centrifuge Facility on present schedule. Initiate planning on new facilities and initiate planning for tails stripping.

Waste Management

Commercial Wastes: Proceed at rapid pace to carry out the IRG recommendations on Waste Management. 
Table 8

SUMMARY OF STRATEGIES ILLUSTRATING RELATIVE

LEVELS OF EMPHASIS FOR EACH PROGRAM ELEMENT

\section{STRATEGY}

PROGRAM

$\begin{array}{cccc}\text { Early } & \text { Late } & \text { Hedged } & \text { Expanded } \\ \text { Breeder } & \text { Breeder } & \text { Breeder } & \text { Nuclear }\end{array}$

Breeder Technology

LMFBR

Alternative Breeders

Reprocessing

$\mathrm{M}$

L

0

$\mathrm{H}$

ถ

L

L

$\mathrm{H}$

M

$\mathrm{H}$

Alternative Technology

LWR Improvements

ACR Development

$\mathrm{L} \quad, \quad \mathrm{H}$

$\mathrm{H} \quad \mathrm{H}$

$\mathrm{H}$

M

L

M

M

H

Resources \& Enrichment

AIST
NURE
Centrifuge Facility
Waste Management

L H

L H

$\mathrm{H} M$

$M$

M

$\mathrm{H}$

M .

$\mathrm{H}$

$M$

H

H

H

$\mathrm{H}$

$$
\begin{aligned}
& H=\text { high effort (emphasis) } \\
& M=\text { medium effort (emphasis) } \\
& L=\text { low effort (emphasis) } \\
& O=\text { terminate program }
\end{aligned}
$$


B. Evaluation of the Strategies

Both the Finite Ore Model and Economics Model results show the same basic conclusions. The achievement of assumed LWR improvements, or an ACR with characteristics similar to those used in the analys is or reduced enrichment tails assay each individually make a considerable contribution to the nuclear economy. When these achievements are combined in various fashions, the contribution becomes quite significant.

The analysis indicates that the transition to the-breeder reactor. can be delayed by a number of years. Only when high nuclear growth, low ore resources, and low breeder capital costs occur simultaneously is there justification for early breeder introduction.

The key factors for evaluating the strategies are Government development costs, resistance to proliferation, the risks of having electric power supply available at the appropriate time, relative comparisons of additional environmental impact, and costs of electricity supply to the country. Although a formal analysis of costs and benefits arising from consideration of each of these factors has not been undertaken, it is possible to make some judgmental evaluation of the strategies based on this analysis and knowledge gained from many other studies un thio eubjent. All evaluations are relative only to the four alternative strategies.

The Early Breeder strategy represents a relatively high cost program with technical and economic risks attendant with moving rapidly to an early deplnyment. Proliferation risk is high because of the necessarily high emphasis on reprocessing and correspondingly low emphasis on alternative technologies. The strategy is favorable towards having another energy 
supply technology available soon but this aspect is somewhat offset by the potential risk of unfavorable development problems that could arise. The strategy has relatively good environmental advantage due to the reduction in mining and milling activities and improved thermal efficiency, although the impacts arising from reprocessing activities tend to lessen this advant age.

The Late Breeder strategy is a low-coot development program because the converter programs are based on wel1-developed, existing technologies. This strategy has the greatest apparent non-proliferatiun advaulages in that reprocessing is indefinitely deferred. Relative to the other strategies, it is the least favorable, based on today's uncertain knowledge about demand and resources, in terms of the risk of having the electric energy available at the appropriate time. The strategy has some disadvantages in environmental impact because of the relatively higher mining and willing requirements but does avoid new impacts from reprocessing. The Hedged Breeder strategy is a relatively moderale cost program requiring more development of alternative technologies $i \overline{i n}$ the next two decades than the Late Breeder Strategy but less development than the Early Breeder Strategy. It is a balanced option that would maintain a strong U.S. position on non-proliferation and at the same timo has a uuderate amount of risk towards having the energy supply, ayailablc when needed. The' strategy has some additional environmental impact which is balanced by the ability to have some flexibility in choices to reduce those impacts. The Expanded Nuclear Strategy is easily the highest cost develupment program in that it requires demonstration and commercialization activities for three alternative reactor concepts. The proliferation risk relative 
to the other strategies is moderate. Even though there is a high emphasis on reprocessing, the high probability of success of the ACR programs could balance this risk. It does provide the lowest risk approach to maintaining a long-term nuclear option and adequate electric energy supply, although the demand for electricity and nuclear energy may not be sufficient to justify such an expanded program. The strategy would have an environmental impact advantage over the other strategies due to the flexibility of choice of appropriate-technology-for-meeting lcoal environmental rëqüirementšs.

With respect to the costs of electricity supply, at this time all strategies are judged relatively equal because the transition to alternative reactors or alternative supporting technologies, in this analysis, is made only when the technologies become economically competitive. More assessment on the effects of reducing costs of technology as a function of the level of development effort is needed before sharper distinctions can be made on the relative electricity costs of each strategy.

A summary of these evaluations is given in Table 9.

Table 9

SUMMARY OF RELATIVE EVALUATION OF STRATEGIES

STRATEGY

\section{Factor}

Government Development Cost Proliferation Resistance

Risk of Electric Supply Environmental Impact

Electricity Costs

\begin{tabular}{|c|c|c|c|}
\hline $\begin{array}{c}\text { Early } \\
\text { Breeder } \\
\end{array}$ & $\begin{array}{c}\text { Late } \\
\text { Breeder }\end{array}$ & $\begin{array}{l}\text { Hedged } \\
\text { Breeder } \\
\end{array}$ & $\begin{array}{r}\text { Expanded } \\
\text { Nuclear } \\
\end{array}$ \\
\hline $\begin{array}{l}\mathrm{H} \\
\mathrm{L}\end{array}$ & $\begin{array}{l}\mathrm{L} \\
\mathrm{H}\end{array}$ & $\begin{array}{l}M \\
M\end{array}$ & $\begin{array}{l}\mathrm{H}^{+} \\
\mathrm{M}\end{array}$ \\
\hline $\begin{array}{l}\mathbf{M} \\
\mathbf{L}\end{array}$ & $\begin{array}{l}\text { II } \\
\mathrm{H}\end{array}$ & $\begin{array}{l}M \\
M\end{array}$ & $\begin{array}{l}\mathrm{L} \\
\mathrm{L}\end{array}$ \\
\hline $\mathbf{M}$ & $\mathbf{M}$ & $\mathbf{M}$ & $\mathbf{M}$ \\
\hline
\end{tabular}

$$
\begin{aligned}
& \mathrm{H}=\mathrm{h} \text { igh } \\
& \mathrm{M}=\text { medium } \\
& \mathrm{L}=\text { low }
\end{aligned}
$$


A good strategy should be one that covers the most potential future outcomes. The Hedged Breeder strategy seems to be the strategy that achieves this feature. The following simple analysis (simple because it treats all future events as equally probable) illustrates why the Hedged Breeder strategy gives the fullest coverage of potential futures.

The Economic Model analysis includes combinations of three breeder capital costs, two uranium price schedules, three nuclear projections for the year 2000 , and three post -2000 nuclear growth patterno. These combinations yield 54 variations fur each alternative reactor future. In addition, two assumptions about uranium enrichment tails assays are cxallined for each case.

The number of these 54 variations that show the breeder economic transition as post-2025, 2010-2025, and pre-2010 are summarized below for earh reactor future and tails assay assumption.

\begin{tabular}{|c|c|c|c|}
\hline \multirow[b]{2}{*}{ Alternative Roactos Futures } & \multicolumn{3}{|c|}{ Yearo of Economic Trancitinis } \\
\hline & post -2025 & $2010-2025$ & pre-2010 \\
\hline Standard LWR & 24 & 19 : & 11 \\
\hline Standard LWR, tails stripping & .30 & 17 & 7 \\
\hline LWR, $15 \%$ fuel improvement & 32 & 17 & 5 \\
\hline $\begin{array}{l}\text { LWR, } 15 \% \text { improvement, tails } \\
\text { stripping }\end{array}$ & $4 ?$ & 9 & 3 \\
\hline LWR, $25 \%$ improvement & 43 & 7 & 4 \\
\hline $\begin{array}{l}\text { LWR, } 25 \% \text { improvement, tails } \\
\text { stripping }\end{array}$ & 46 & 7 & 1. \\
\hline
\end{tabular}


Based on the potential ranges of the key variables and likely technological development paths, the analysis shows that the large majority of the cases project an economic transition to the breeder in post -2025 . Thus, a strategy to delay the decision to build a breeder demonstration reactor is most consistent with the largest space of future events analyzed in this study.

However, there are a significant number of situations wherein the breeder would be needed between 2010-2025. It is prudent to pursue a strategy that continues extensive development of breeder design and components. This would readily permit a decision to move the program at a more rapid pace if future knowledge gives indications that an early breeder is needed.

There are very few situations that indicate an economic transition to the breeder before 2010. Thus, a strategy to move forward:rapidly with breeder development is not, supported by the analysis.

\section{VI. 'PROGRAM IMPLEMENTATION OF THE STRA'TEGY}

The DOE nuclear program is designed to continue the development of technology and information in three main areas:

1. programs capable of moderate extension of the uranium resource base through enhanced utilization of uranium. in light water reactors, advancements in isotope separation techniques, and increased knowledge of our domestic uranium resources;

2. programs capable of major extension of the uranium resource base through the development, of breeder reactors; and 
52.

3. enabling programs, such as waste management, nonproliferation, and health and safety, required in support of the nuclear option.

\section{A. Programs for Moderate Near-Term Resource Extension}

- Light Water Reactor (LWR) Improvements

The installed capacity of LWRs in the U.S. is expected to increase from $55,000 \mathrm{MW}$, which accounted for $13 \%$ of the U.S. electrical cnergy production in $19 / 8$, to approximately $110,000 \mathrm{MW}$ in 1985. The predictions for the year 2000 are from a low of $255,000 \mathrm{MW}$ to a high of $395,000 \mathrm{MW}$; although new projections may reduce these values. DOE efforts to strengthen the performance of LWRs will thus impact a very significant segment of the U.S. electrical energy generating capacily.

The udjor effort in the area of LWR technology is the improvement of fuel utilization. The objective is a reduction in uranium consumption by as much as $15 \%$ by 1988 , and by a further $15 \%$ by the year 2000 . Initial cmphasis is being placed on higher fuel burn-up, which is the most straightforward, near-term means for improving fuel utilization. The teclinical issues which will be addressed art pellet-clad interaction, fission gas release, currosion and hydriding of fuel cladding, and fuel assembly dimensional and structural changes. Work will also be done on other methods for improving uranium utilization, including: fuel lattice changes, spectrum changes, enrichment zoning, cycle stretchout, and more frequent refuelings. 
Significant work is also being undertaken to increase the LWR plant capacity factor, to reduce occupational radiation exposure, and to develop improved safety, concepts and systems. The main effort in the area of increased LWR energy production is concentrated on the steam generator tube "denting" problem. Reduction in radiation exposure is being addressed through the development of chemical decontamination processes and advanced surveillance and diagnostic techniques. The LWR safety work includes the study of advanced concepts, investigation of the man-machine interface, evaluation of system sensitivity, and the acquisition of safety data on higher burn-up fuels.

- Advanced Isotope Separation Technology

Another approach to the extension of uranium resources for use in LWRs is development of advanced isotope separation technology (AIST) methods that could be applied to the existing large stockpile of tailings, as well as future tailings, from uranium enrichment plants. These tailings still contain $0.2-0.3 \%$ fissile U-235. Extraction and utilization of this fissile material to $0.05 \%$ tails assay could increase the efficiency of total uranium resource use by about $20 \%$. The program calls for development of three AIST techniques through the preprototype phase. This will be followed by thorough evaluation of scaleability, economic potential, proliferation resistance, and environmental effects. A decision to proceed with engineering development of the best of the three technologies will be based on the evaluation. 
- National Uranium Resource Evaluation

The National Uranium Resource Evaluation Program (NURE) is the major program activity that provides a systematic appraisal of domestic uranium resources. For program management purposes, the United States and Alaska are divided into over 600 quadrangles of which about 270 are classified "A" qandrangles because they contain uranium resources or are geologically favorable for uranium. A preliminary report assessing priority areas is scheduled to be. published by. the end of 1982 , to be followed by a final report at the end of 1983. A final NURE rcpoit embracing both the United States and Alaska should be complered by the end of 1985 . When the program is completed in 1985, all "A" and "B" category quandrangles will have been subjected to surface evaluations, aorial surveys, hydrocliemical investigations, and appropriate subsurface genlogic investigatinns.

In addition to the NURE program, the uranium resource assessment program sponsors technology developinent associiated with uranium exploracion, mining, and production. The program participates in the Internatinnal Urauium Resources Evaluation Project (IUREP), which is an international collaborative effort to review and evaluate world-wide uranium resources.

\section{B. Programs for Major.Extension of the Resource Base}

Through breeding, the energy latent in our thorium resources and in the U-238 present in our natural uranium resources can be made available to provide a practically inexhaustible source of electricial or high 
quality heat energy. The breeder development program currently includes work on three breeder systems: the Liquid Metal Fast Breeder Reactor (LMFBR), the Light Water Breeder Reactor (LWBR), and the Gas Cooled Fast Reactor (GCFR).

- LMFBR Program

The continuing development of the LMFBR is focused on an indepth conceptual design study (CDS) that will result in a design for a demonstration plant. A parallel base technology program complements the conceptual study and is capable of, supporting the expeditious pursuit of detailed design and construction should the decision by made to proceed.

The CDS is planned to be completed in two phases. The first phase, which will be completed in FY 1980, will consist primarily of evaluation and trade-off studies to select key'technical parameters for a developmental LMFBR plant. The second phase will be started in FY 1980 and completed by March 31, 1981, with the submission of a conceptual design report to the Congress. The conceptual design report, together with the nonproliferation studies (NASAP, INFCE), the uranium/thorium resource assessment program (NURE), and continued achievements in the base R\&D program will provide the basis for a possible decision in 1981 as to the future fast breeder reactor role and development strategy, including the scope and pace of the LMFBR program. The Fast Flux Test Facility (FFTF) is a $400 \mathrm{MW}$ liquid metal (sodium) cooled fast-neutron-flux reactor designed specifically for irradiation testing of nuclear fuels and materials for liquid 
metal fast breeder reactors. It will play a key role in development and testing activities. It will provide a test bed for demonstrating and evaluating the performance of future LMFBR plant fuel assemblies and core designs at reference conditions.

The breeder technology program will provide engineering information and technology support needed to increașe the salecy and reliabilily, reduce the cost, and facilitate licensing of future LMFBR plants and facilities. Effort will continue on safety, engineering syotems and componenes, physics, fuels and core design, and materials and chemistry. This will include studies of alcernative fuel technologies to investigate their nonproliferation characteristics. The Transient Reactor Test Facility (TREAT) is being upgraded to provide advanced in-reactor capability for fast transient testing of reactor fuel nerqenosiy fór satety evaluations. TREAT is part of the Safety Research Fxpcriment facilities (SAREF). Kealignment of the breeder rcactur safety program lias established the prioritiy for construction of the SAREF Project so that it will be accomplished in phases and has eliminared the requirement for modification of the Experimental Breeder, Reactor to a safety reactur facility. Phase $I$ is the TREAT Upgrade (TU). Phase II will pruvide the additional facilities required to support the spectrum of in-rcactur safety experiments.

The Administration has proposed that the Clinch River Project be terminated except for selected design, - component and generic licensing activities of value to the overall LMFBR program. It is the 
Administrations objective that appropriate legislation for termination be enacted as early as possible.

- LWBR Program

The objective of the LWBR program is to develop the technology for making avallable the energy in the Nation's thorium reserves through the use of existing pressurized light water reactor technology The program consists of the Shippingport Atomic Power Station program, the Light Water Breeder Reactor (LWBR) base program, and . the Advanced Water Breeder Applications (AWBA) program.

An LWBR core fueled with U-233 and thorium, and cooled and moderated with ordinary light water, has been operating successfully $\cdot$ in the Shippingport Atomic Power Station since August 1977. The current plan is to operate this core for three to four years before its removal for detailed examination and verification of breeding performance. Under the LWBR program, periodic tests of an LWBR core w11l be conducted, evaluated, and compared to performance predictions. The AWBA program will develop and disseminate technical information as a guide to the industry in the application of the technology.

- GCFR Program

The GCFR program is a cooperative effort among a group of electric utilities, the Helium Breeder Associates, and DOE to develop the potential of this system as a long-term nuclear power option. Work on the program definition and licensing phase is now underway and is expected to continue through 1985, when a decision 
will be made as to the future role of the GCFR, in the U.S. energy program. An international cooperative effort on the GCFR has also been established.

\section{Enabling Program}

- Nuclear Waste Management

The program for nuclear waste management is designed to protect the public health and safety, and the environment, from radioactive, materials that result from National defense programs, R\&D, and commercial activities. Reecognizing the numerous Federal agencies, as well as State and local interests involved in this program; the President established an Interagency Review Group (IRG) in March 1978. He charged it with developing a strategy for dealing with the waste management problem. The IRG will soon publish its final report and will short ly present its findiugs and recommendations to the President in the form of a decisinn papcr. It is expected that this paper will result in the approval of finterim strategic planning bases for the various kinds of waste and in decisions to seek the legislative authorizatione required to proceed with the various phasco of the program. In the interim, the DOE program for nuclear waste is being further expanded to develop the broad base of techulogy needed in support of this cffort.

With respect to DOE's Defense Waste Management Program, steps are being taken to continue to store these wastes safely on an interim basis, while providing the technologies for the selection and implementation of alternatives for their long-term disposal. 
This prinçiple applies to high-level, transuranic, and lowlevel wastes in the Defense category. It also expected that a suitable site will be found, from both a regulatory and institutional viewpoint, for the construction of a Waste Isolation Pilot P.lant, to be operational by 1986 , for the permanent disposal of transuranic defense wastes. In addition, consideration is being given to utilizing such a facillty for the purposes of RD\&D on high-level defense wastes, as well as for the disposal, initially on a retrievable basis, of up to 1,000 commercial spent fuel assemblies.

In the area of Commercial Waste Management, the DOE program is similarly directed toward providing the technology and facilities necessary to meet applicable safety and environmental requirements for the long-term management of these wastes. Present efforts center upon the identification of candidate sites from several alternative geologic media for the first repository, the development of waste treatment technology, and terminal storage of RD\&D. It is expected that such activities will be accelerated within the foreseeable future. 
Appendix A

MODEL RESULTS

\section{A. Finite Ore Model}

This section presents the results from the Finite Ore Model calculations, including both the dates of the last year an LWR or ACR could be installed assuming no additional uranium discoveries and no recycle of uranium and the adjustment to those date's to show the year of first breeder commercial operation. The analysis used assumptiono of three nuclear capacity values in 2000 , three nuclear growth rate schedules for post-2000, three values of the finite size of uranium resources, and four alternative reactor deployment schemes. Each of these combinations was analyzed using two different uranium enrichment tails assay values.

In Table A-1 (identical to Table 5 in the text), the dates show the last year that LWRs or ACRs could be installed and still have sufficient uranium to fuel reactors for a 30 -year lifetime, based on a $0.2 \%$ tails assay.

Certain adjustments must be made to this table to reflect the date of brceder.introduction. These adjustments are presented in Tables A-2 through A-4. If breeder introduction were imminent, then fuel reprocessing facilities would be constructed and operated. These reprocessing facilitieo would return I-w235 for recycle in LWRs or ACRs. The availability of this additional fissile material would extend the dates for last installation of an LWR or ACR while still having a 30-year supply of fuel. These extensions of dates for each of the cases' is shown in Table A-2. 
The Breeder reactor must have a phasing-in period and LWRs or ACRs, must have a phasing-out period to achieve an orderly substitution of technology. The phasing-out of LWRs or ACRs results in another extension of about two years to the dates of last installation. This adjustment to the dates is shown in Table A-3.

Finally, the phasing-in of breeder reactors, using a normal penetration rate, requires that the first commercial breeder reactor must be installed several years before the last installation of a converter reactor. This phasing-in schedule would permit breeder reactors to satisfy all market demand for new and replacement nuclear power by the last year that a converter reactor can be installed. The dates of breeder introduction for each of the cases is given in Table A-4.

An example, in graphical form, of these adjustments is shown in Figure A-1. Using one of the cases from the Finite Ore Model, the LWR additions through date of last installation are shown for the once-through fuel cycle, the extension due to uranium recycle, and the extension due to phasing-out. The chart also shows the phasing-in for breeder reactors, thus providing the date of first commercial breeder.

The same sequence of dates, usling the $0.05 \%$ uranium talls assay, is presented in Tables A-5 through A-8. 
ANALYSIS OF COMMERCIAL BREEDER INTRODUCTION BASED ON FINITE ORE MODEL

(3.6 MILLION ST U $\mathrm{U}_{3} \mathrm{O}_{8}, 300$ MWe INSTALLED NUCLEAR CAPACITY IN YEAR 2000, 15 GWe NET ADDITIONS PER YEAR AFTER 2000 $0.2 \%$ ENRICHMENT PLANT TAILS ASSAY, LWR URANIUM UTILIZATION IMPROVED 15\% IN 1985 AND 25\% IN 2000)

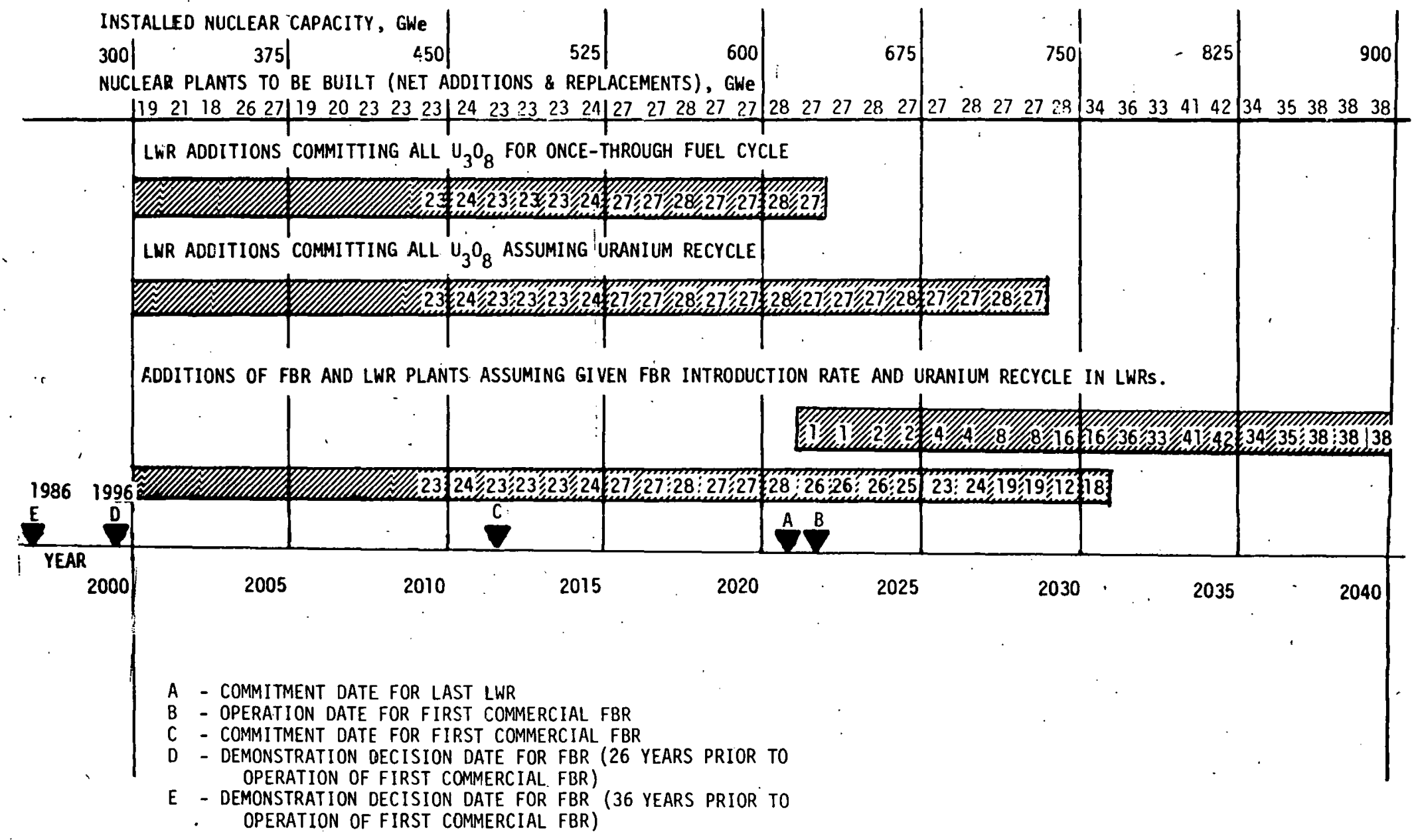


TABLE, A-1

DATE OF TOTAL $\mathrm{U}_{3} \mathrm{O}_{8}$ COMMITMENT

(0.2 Tails - Once Through)

Uranium Ore Base (Millions of Short Tons of $\mathrm{U}_{308}$ )

Growth Rate(GWe/yr):

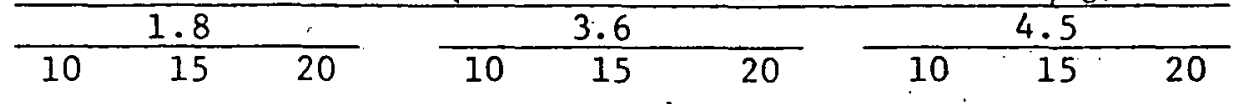

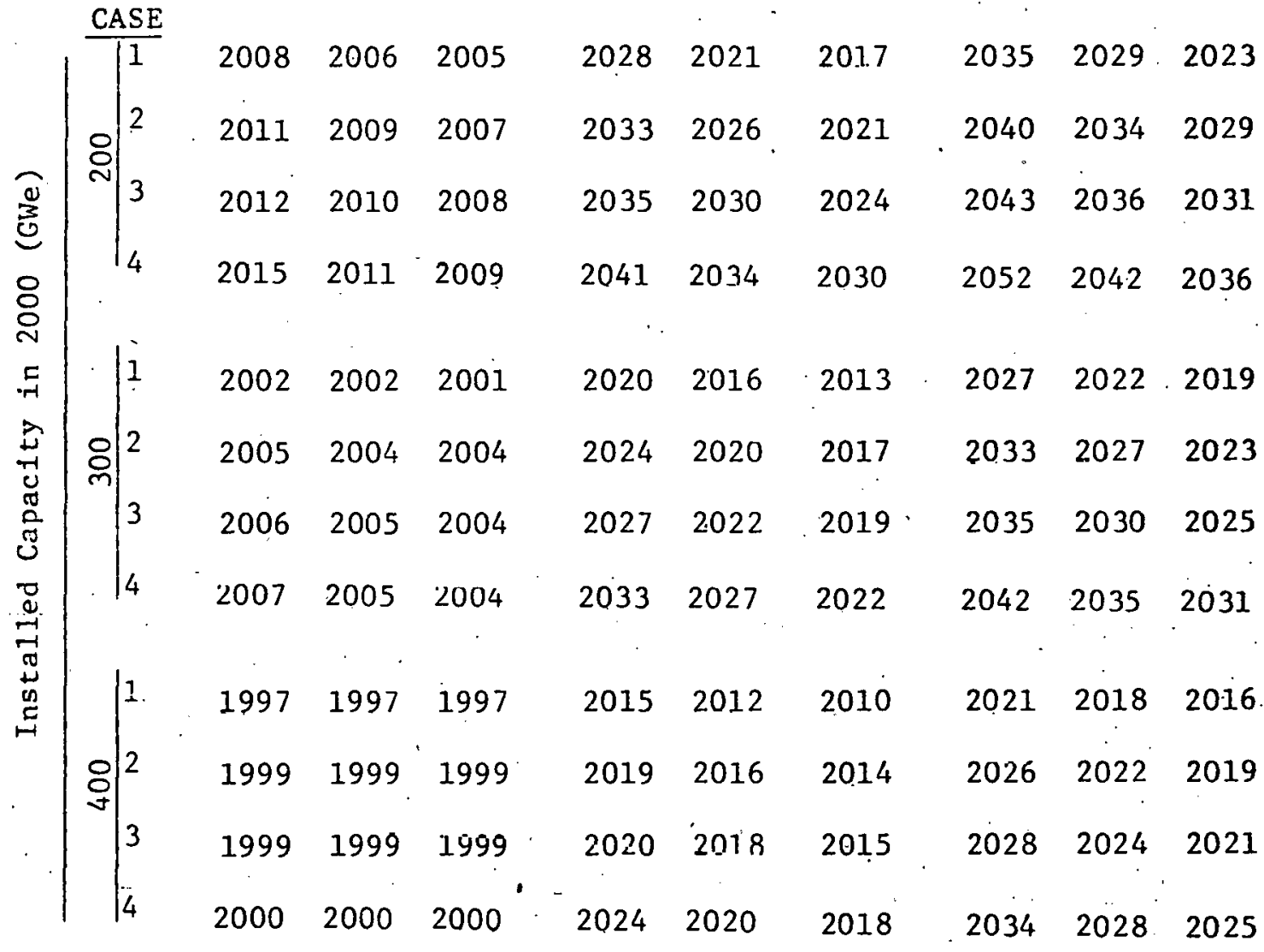

Case 1: LWR (5500 tons) only

Case 2: LWR (5500 tons) to 1985 - Then all convert to improved LWR (4675 tons)

Case 3: Case 2 and optimized LWR (4200 tons) for all atter Year 2000

Case 4: Case 2 and ACR (3300 tons) Introduction in 1995 
TABLE A-2

DATE OF TOTAL U $3^{0} 8$ COMMITMENT

(0.2 Tails - U Recycle)

Uranium Ore Base (Millions of Short Tons of U 308 )

Growth Rate (GWe/yr): 1.8

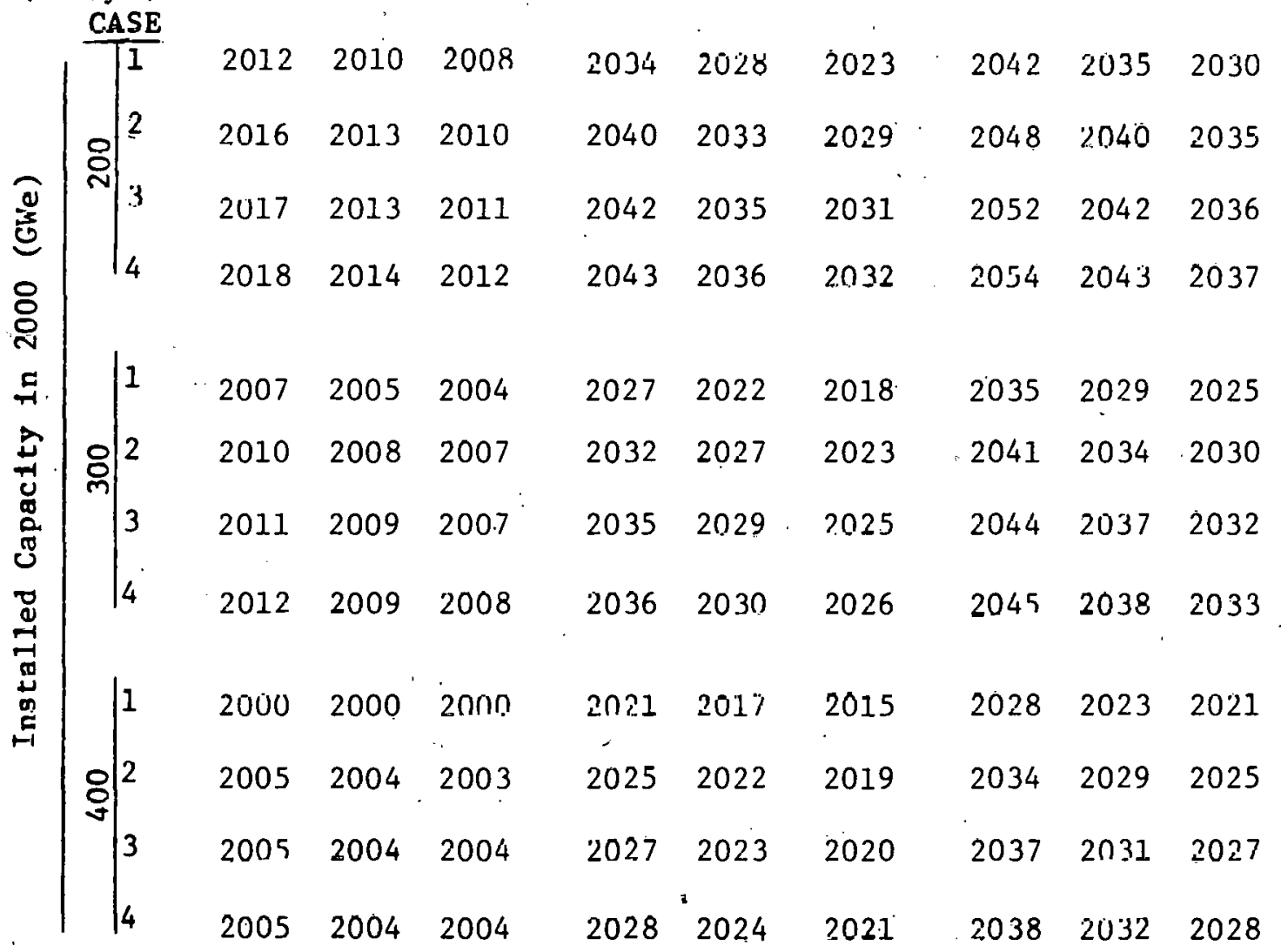

Case 1: LWR (550n tone no recycle; 4430 tons with recycle) only. Case 2: LWR (5500 tons no rccycle) to 1985 - then all convert to Improved LWR ( 4675 tons no recycle; 3765 tons with recycle).

Case 3: Case 2 and optimized LWR (4200 tons no recycle; 3390 tons with recycle) for all after year 2000 .

Case 4: Case 2 and ACR (3300 tons no recycle; 3300 tons with recycle) introduction in 1995 
TABLE A-3

\section{DATE OF TOTAL $\mathrm{U}_{3} \mathrm{O}_{8}$. COMMITMENT}

Uranium Recycle in LWRs and Commercial FBR Introduction ( $0.2 \%$ enrichment plant tails assay)

Uranium Supply:

(Million tons $\mathrm{U}_{3} \mathrm{O}_{8}$ ) Growth Rate (GWe/yr):
- Uranium Ore Base (Millions of Short Tons of U308)

\begin{tabular}{rr}
\hline & 1.8 \\
\hline $10 . \quad 15$ & 20
\end{tabular}

\begin{tabular}{ll}
3.6 \\
\hline $10 \quad 15$ & 20
\end{tabular}

$\frac{4.5}{10-\frac{15}{20}}$

CASE

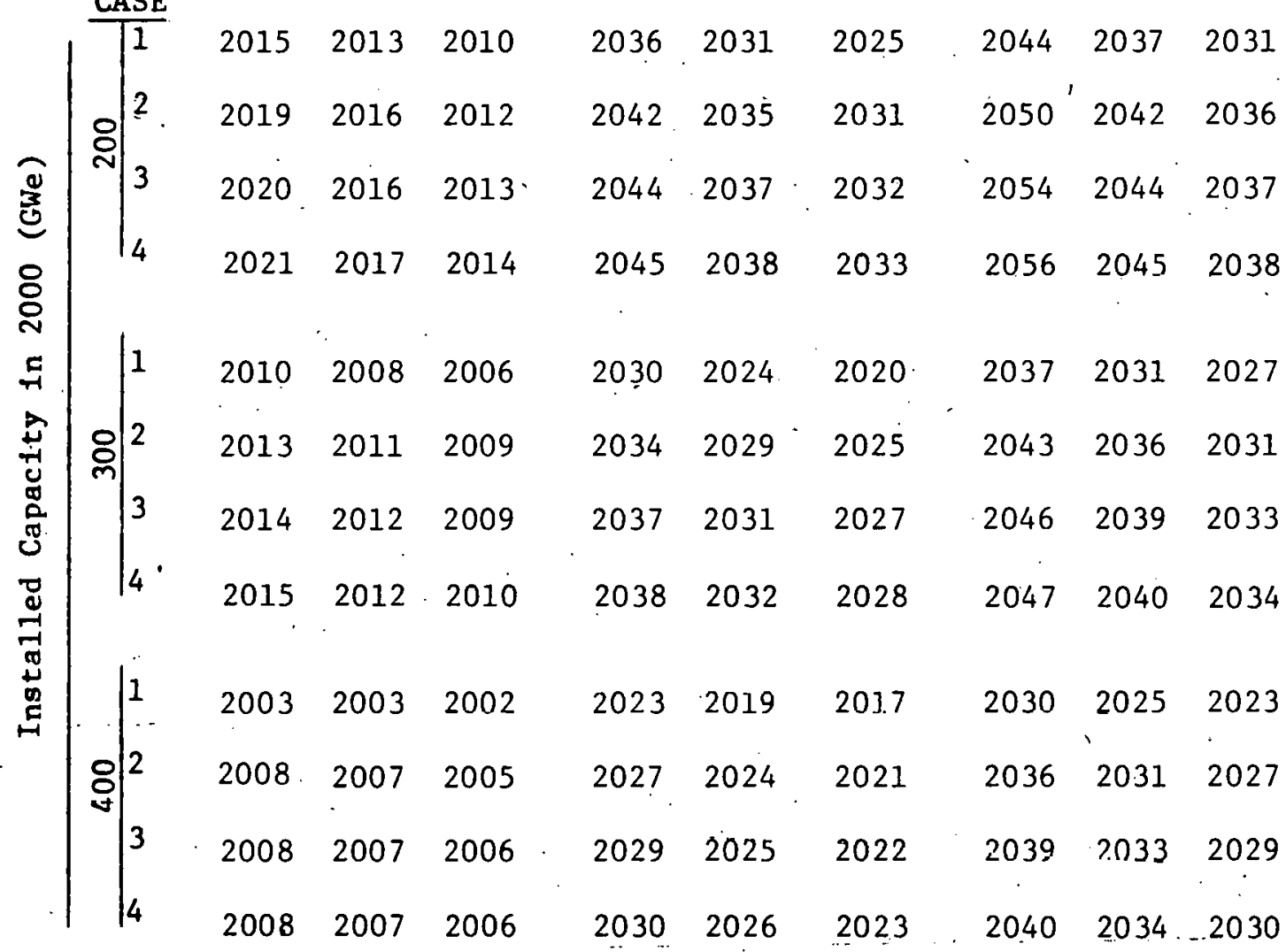

Case 1: LWR (5500 tons no recycle; 4430 tons with recycle) only Case 2: LWR (5500 tons no recycle) to 1985 - Then all convert to improved LWR (4675 tons no recycle; 3765 tons with recycle)

Case 3: Case 2 and optimized LWR (4200 tons no lecycle; 3390 tons with recycle) for all after Year 2000.

Case 4: Case 2 and ACR (3300 tons no recycle; 3300 tons with recycle) introduction in 1995 
TABLE A-4

DATE OF OPERATION FOR FIRST COMMERCIAL BREEDER

Uranium Recycle
$(0.2 \%$ enrichment plant tails assay)

Uranium Supply:

(Miliion $\mathrm{STU}_{3} \mathrm{O}$ )

Growth Rate (GWe/yr):

Uranium Ore Base (Millions of Short Tons of $\mathrm{U}_{308}$ )

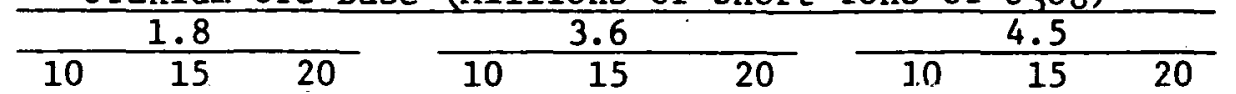

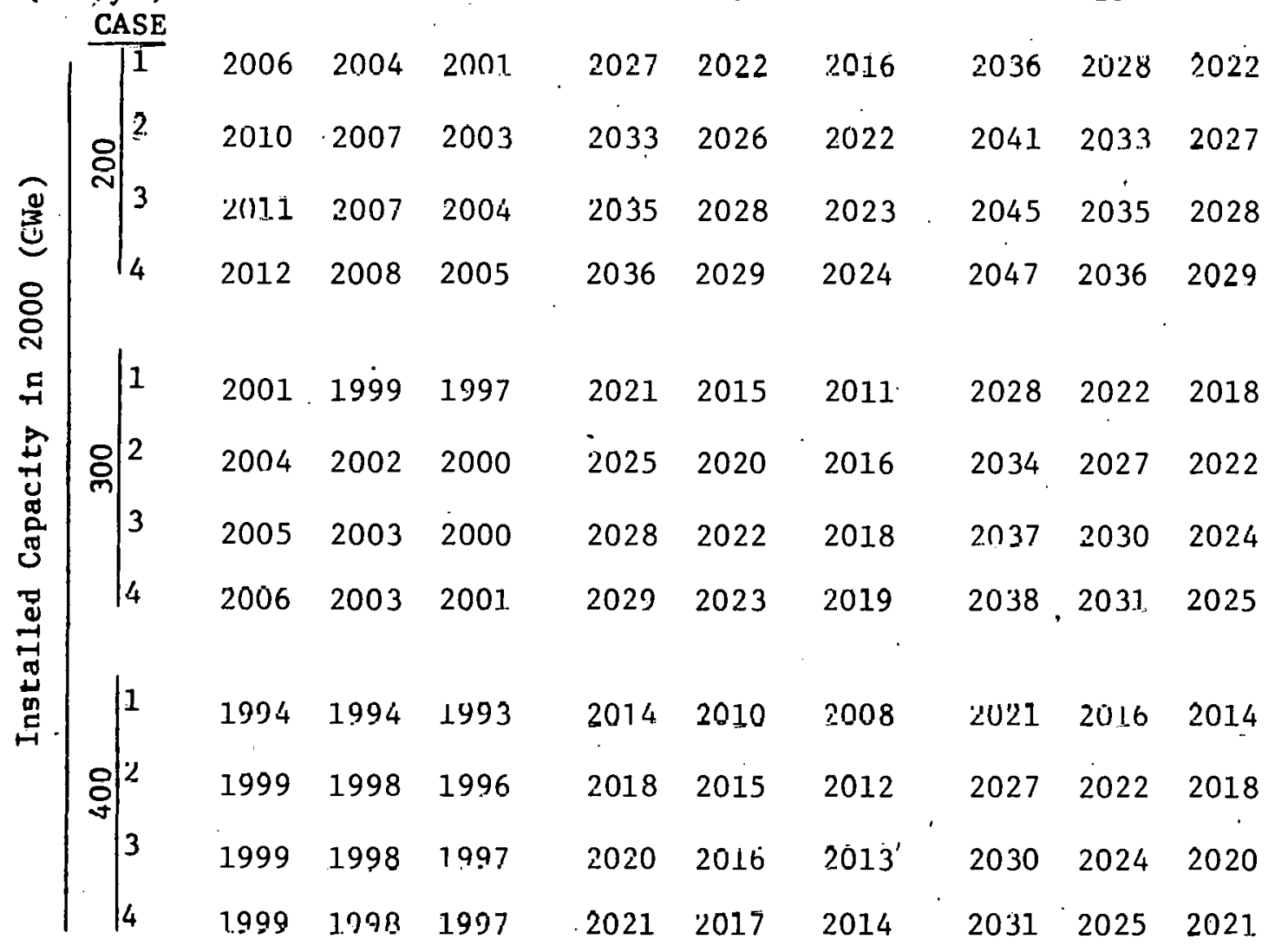

Case 1: LWR (5500 tons no recycle; 4430 tons wilh recycle) only

Case 2: LWR ( 5500 tons no recycle) to 1985 - Then all convert to improved LWR ( 4675 tons no recycle; 3765 tons with recycle)

Case 3: Case 2 and optimized LWR (4200-tons no recycle; 3390 tons with recycle) for all after Year 2000.

Case 4: Case 2 and ACR (3300,tons no recyclc; 3300 tons with rccycle) Introduction in 1995. 
TABLE A-5 :

DATE OF TOTAL $\mathrm{U}_{3} \mathrm{O}_{8}$ COMMITIENT

(.05\% Tails - Once Through)

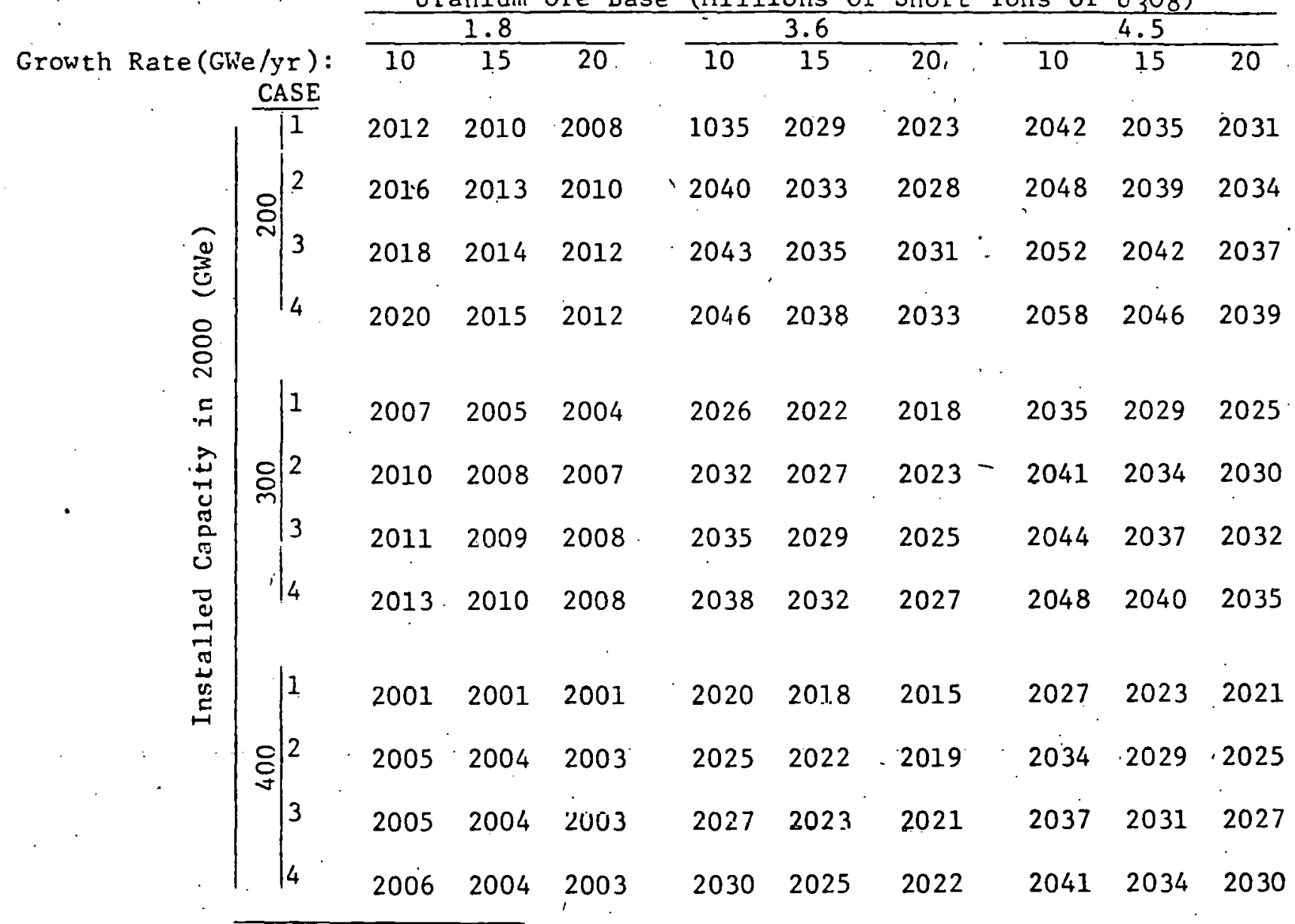

Case 1: LWR (4.450 tons) only

Case 2: LWR (4450 tons) to 1985 - Then all convert to improved LWR (3795 tons).

Case 3: Case 2 and optimized LWR (3400 tons) for all after year 2000

Case 4: Case 2 and ACR ( 3030 tons) intrnduction in 1995. 
TABLE A-6

$\frac{\text { DATE OF TOTAL U }}{\left(0.05 \% \text { Tails }-3^{0}\right.} \frac{\text { COMMITMENT }}{\text { Recycle })}$

Uranium Ore Base (Millions of Short Tons of $\mathrm{U}_{308}$ )

Growth Rate (GWe/yr):

\begin{tabular}{lrl}
\hline & 1.8 \\
\hline 10 & 15 & 20
\end{tabular}

CASE

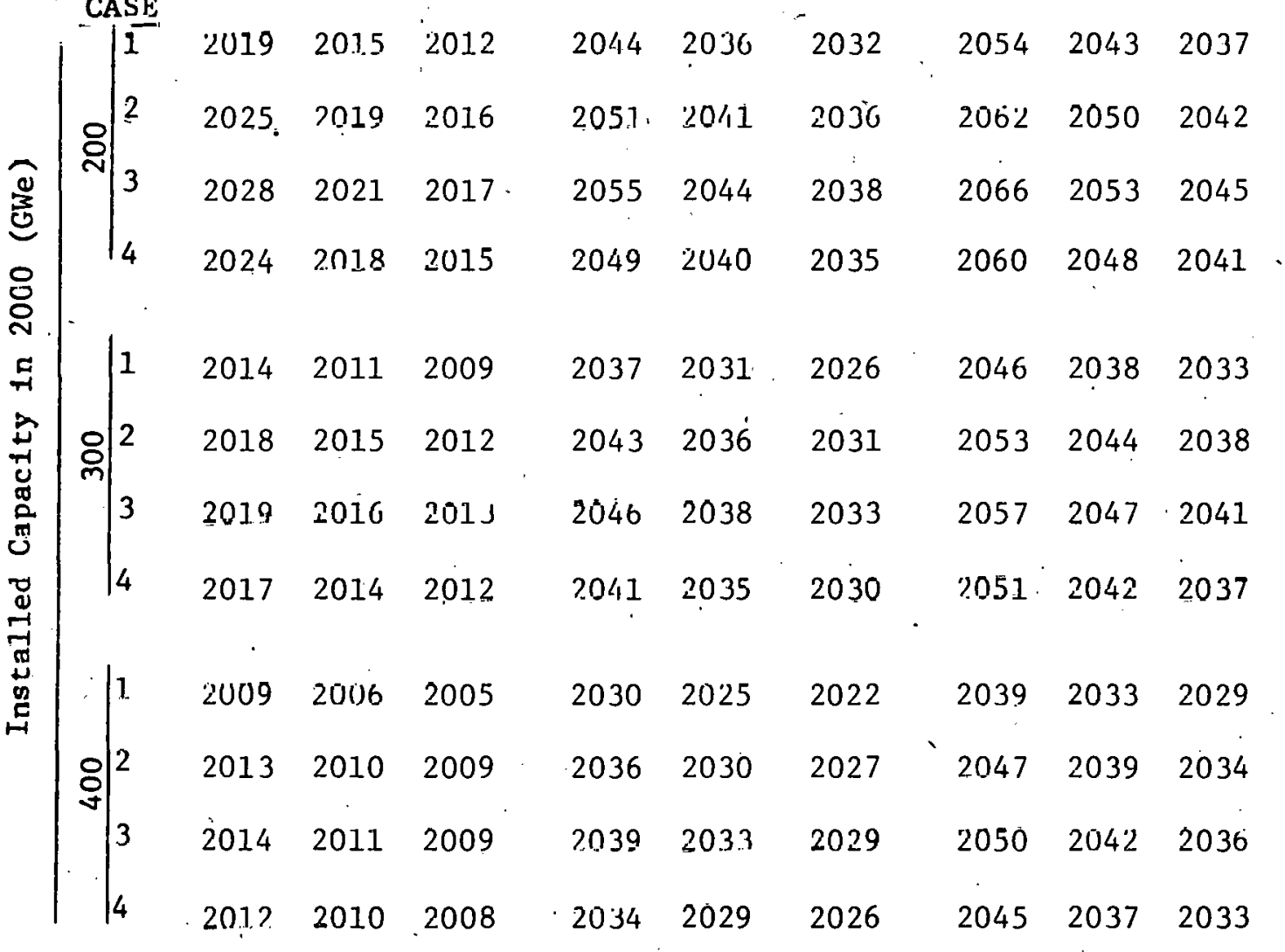

Case 1: LWR (4450 tons nn recycle; 3380. tons wlth.recycle) only-

CaEc $2:$ LWR (4450 tons no recy.le) to 1985 - then all conver-t.to 1mproved LWR ( 3795 tons no recycle; 2875 tons with recycle)

Case 3: Case 2 and optimized LWR (3400 tons no recycle; 2585 tons with recycle) for all after year 2000

Case 4: Case 2 and ACR (3030 tons no recycle; 3030 tons with recycle) introduction in 1995 . 
TOTAL $\mathrm{U}_{3} 0_{8}$ COMMITMENT DATES

URANIUM RECYCLE IN LWRS AND COMMERCIAL FBR INTRODUCTION (0.05\% enrichment plant tails assay)

Uranium Supply:

(Million S.T. $\mathrm{U}_{3} \mathrm{O}_{8}$ ) Growth Rate (GWelyr):

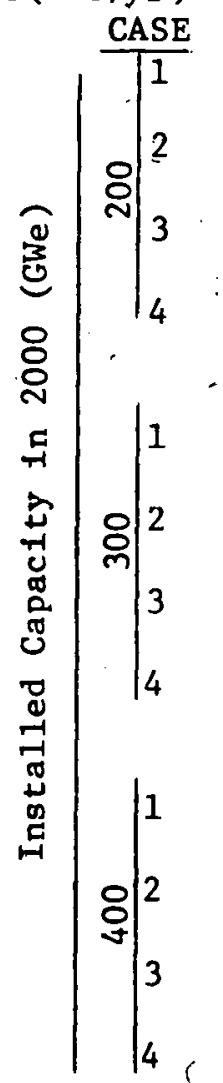

Uranium Ore Base (Millions of Short Tons of U 308 )

\begin{tabular}{lr}
\hline & 1.8 \\
\hline $10 \quad 15$ & 20
\end{tabular}

3.6
$.10 \quad 15$

\begin{tabular}{l}
4.5 \\
$10 \quad 15$ \\
\hline
\end{tabular}

$\begin{array}{llllll}2022 & 2018 & 2014 & 2046 & 2038 & 2033\end{array}$

$\begin{array}{llllll}2028 & 2022 & 2018 & 2053 & 2043 & 2037\end{array}$

$2031-2024 \quad 2019 \quad 2057 \quad 2046 \quad 2039$

$\begin{array}{lllllllll}2027 & 2021 & 2017 & 2051 & 2042 & 2036 & 2062 & 2050 & 2042\end{array}$

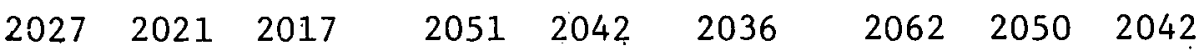

$20562045 \quad 2038$

$20642052 \quad 2043$

206820552046

$\begin{array}{lllllllll}2017 & 2014 & 2011 & 2039 & 2033 & 2027 & 2048 & 2040 & 2034\end{array}$

$\begin{array}{lllllllll}2021 & 2017 & 2014 & 2045 & 2038 & 2032 & 2055 & 2046 & 2039\end{array}$

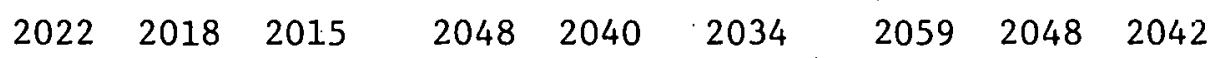

$\begin{array}{lllllllll}2020 & 2017 & 2014 & 2043 & 2037 & 2031 & 2053 & 2044 & 2038 .\end{array}$

$\begin{array}{lllllllll}2012 & 2009 & 2007 & 2032 & 2027 & 2024 & 2041 & 2035 & 2030\end{array}$

$\begin{array}{lllllllll}2016 & 2013 & 2011 & 2038 & 2032 & 2029 & 2049 & 2041 & 2035\end{array}$

$\begin{array}{lllllllll}2017 & 2014 & 2011 & 2041 & 2035 & 2031 & 2052 & 2044 & 2037\end{array}$

$\begin{array}{lllllllll}2015 & 2013 & 2010 & 2036 & 2031 & 2028 & 2047 & 2039 & 2034\end{array}$

Case 1: LWR (4450 tons no recycle; 3380 tons with recycle) only

Case 2: LWR (4450 tons no recycle) to 1985 - Then all convert to improved LWR ( 3795 tons no recycle; 2875 tons with recycle)

Case, 3: Case 2 and optimized LWR (3400. tons no recycle; $2585^{\circ}$ tons w1th recycle) for all after Year 2000

Case 4: Case 2 and ACR (3030 tons no recycle; 3030 tons with. recycle) introduction in 1995. 
TABLE A-8

DATE OF. OPERATION FOR FIRST COMMERCIAL BREEDER

Uranium Recycle

(0.05\% enrichment plant tails assay)

Uranium Supply

(Million $\mathrm{STU}_{3} \mathrm{O}_{8}$ ):

Growth Rate (GWe/yr):
Uranium Ore Base (Millions of Short Tons of U308)

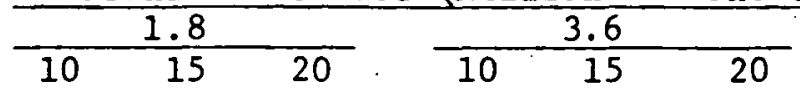

\begin{tabular}{lrl} 
& 4.5 \\
\hline 10 & 15 & 20
\end{tabular}

$\begin{array}{lllllllll}2013 & 2009 & 2005 & 2037 & 2029 & 2024 & 2047 & 2036 & 2029\end{array}$

$\begin{array}{lllllllll}2019 & 2013 & 2009 & 2044 & 2034 & 2028 & 2055 & 2043 & 2034\end{array}$

$\begin{array}{lllllllll}2022 & 2015 & 2010 & 2040 & 2037 & 2030 & 2059 & 2046 & 2037\end{array}$

$\begin{array}{lllllllll}2018 & 2012 & 2008 & 2042 & 2033 & 2027 & 2053 & 2041 & 2033\end{array}$

$\begin{array}{lllllllll}2008 & 2005 & 2002 & 2030 & 2024 & 2028 & 2039 & 2031 & 2025\end{array}$

$\begin{array}{lllllllll}2012 & 2008 & 2005 & 2036 & 2029 & 2023 & 2046 & 2037 & 2030\end{array}$

$\begin{array}{lllllllll}2013 & 2009 & 2006 & 2039 & 2031 & 2025 & 2050 & 2039 & 2033\end{array}$

$\begin{array}{lllllllll}2011 & 2008 & 2005 & 2034 & 2028 & 2022 & 2044 & 2035 & 2029\end{array}$

$\begin{array}{lllllllll}2003 & 2000 & 1998 & 2023 & 2018 & 2015 & 2032 & 2026 & 2021\end{array}$

$2007 \quad 2004 \quad 2002 \quad 2029 \cdot 2023 \quad 2020 \quad 2040 \quad 2032 \quad 2026$

$\begin{array}{lllllllll}2008 & 2005 & 2002 & 2032 & 2026 & 2022 & 2043 & 2035 & 2028\end{array}$

$200620042001,2027202 z^{2} 2019^{\prime \prime} 203820302025$

Case 1: LWR (4450 tons no recycle; 3380 tons with recycle) only

Case 2: LWR (4450 tons nu recycle) to 1985 - Then all convert

to improved T:WR ( 3795 tons no recycle; 2875 tons with recycle)

Caoe 3: Case 2 and optimized LWR (3400 tons no recycle; 2585 tons with recycle) for all after Year 2000

Case 4: Case 2 and ACR (3030 tons no recycle; 3030 tons with recycle). introduction in 1995 


\section{B. Economics Model}

This section presents the results from the Economics Model calculations. The analysis used assumptions of three nuclear capacity values in 2000 , three nuclear growth rate schedules for post-2000, two alternative uranium price-quantity supply schedules, three values of relative capital costs of breeders to LWRs, and three alternative reactor deployment schemes. (The Economics Model is not currently structured to analyze the ACR introduction, Case 4, but is being modified to analyze this case in the prescribed manner.) Each of these combinations. was analyzed using two different uranium enrichment tails assay values.

The results for the three reactor deployment schemes using a $0.2 \%$ tails assay are given in Table A-9 through A-11. The cases using the $0.05 \%$ tails assay are shown in Table A-12 through A-14. 
TABLE A-9

Installed Capacity In 2000 (GWe):

\begin{tabular}{|c|c|c|c|c|c|c|c|c|c|c|}
\hline \multirow{2}{*}{\multicolumn{2}{|c|}{ Growth Rate (Glie/yr): }} & \multicolumn{3}{|c|}{200} & \multicolumn{3}{|c|}{300} & \multicolumn{3}{|c|}{400} \\
\hline & & 10 & 15 & 20 & 10 & 15. & 20 & 10 & 15 & 20 \\
\hline $\begin{array}{l}\text { FBR Capital } \\
\text { Cost }\end{array}$ & $\mathrm{U}_{3} \mathrm{O}_{8}$ Price & $>2025$ & $>2025$ & $>2025$ & $>2025$ & $>2025$ & $>2025$ & $>2025$ & $>2025$ & $>2025$ \\
\hline \multirow[t]{2}{*}{1.75} & \multirow{2}{*}{$\begin{array}{c}\text { Intermediate } \\
\text { High }\end{array}$} & & & r & & & & & & \\
\hline & & $>2025$ & $>_{2025}$ & $>2025$ & $>: 025$ & $>2025$ & $>2025$ & $>2025$ & 2023 & 2020 \\
\hline \multirow[t]{2}{*}{1.50} & Intermediate & $>2025$ & $>2025$ & $>2025$ & $>2025$ & $>2025$ & $>_{2025}$ & $>2025$ & 2024 & 2020 \\
\hline & & $>2022$ & $>2018$ & $>2014$ & $>2014$ & $>2012$ & $>2010$ & $>, 2010$ & 2008 & 2007 \\
\hline \multirow[t]{2}{*}{1.25} & \multirow{2}{*}{$\begin{array}{c}\text { Intermediate } \\
\vdots \\
\text { High }\end{array}$} & $>2025$ & 2021 & 2016 . & 2017 & 2014 & 2013 & 2013 & 2011 & 2008 \\
\hline & & 2012 & 2009 & 2007 & 2004 & 2003 & 2002 & 1997 & 1997 & 1997 \\
\hline
\end{tabular}

Date of Economic Transition to the FBR from the Standard Light water Reactor on the Once-Through Cycle with $0.2 \%$ Tails 
TABLE $\quad A-10$

Installed Capacity In 2000 (GWe):

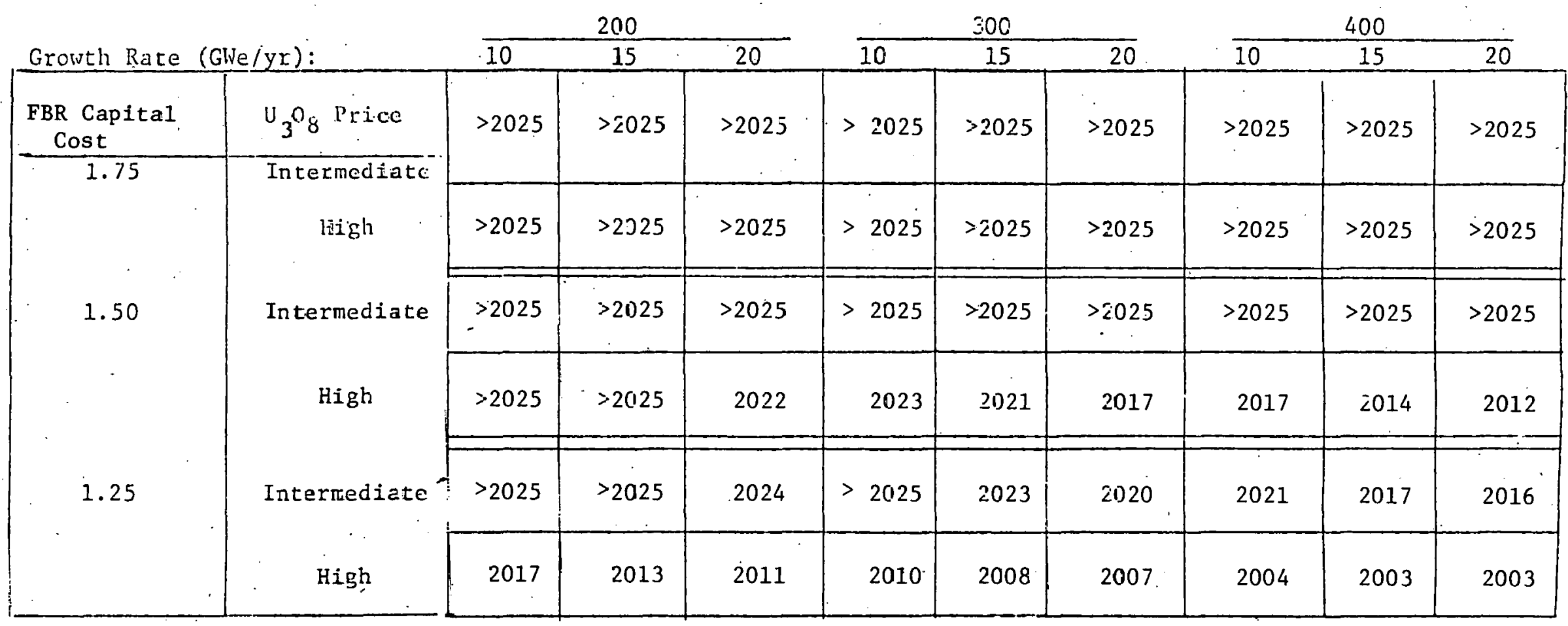

Date of Economic Iransition to the: FBR from the LWR with $15 \%$ Improvement in $3_{8}$ Utilization on the Once-Through Cycle with $0.2 \%$ Tails 
TABLE A-11

Installed Capacity In 2000 (GWe):

\begin{tabular}{|c|c|c|c|c|c|c|c|c|c|c|}
\hline \multirow{2}{*}{\multicolumn{2}{|c|}{ Growth Rate (G) }} & \multicolumn{3}{|c|}{200} & \multicolumn{3}{|c|}{300} & \multicolumn{3}{|c|}{400} \\
\hline & & 10 & 15 & 20 & 10 & 15 & 20 &.$\overline{10}$ & 15 & 20 \\
\hline $\begin{array}{c}\text { FBR Capital } \\
\text { Cost }\end{array}$ & $\mathrm{U}_{3} \mathrm{O}_{8}$ Price & $>2025$ & $>2025$ & $>2025$ & $>2025$ & $>2025$ & $>2025$ & $>2025$ & $>2025$ & $>2025$ \\
\hline \multirow{2}{*}{1.75} & Intermediate & & & & & & & & & \\
\hline & \multirow[b]{2}{*}{ Intermediate } & $>2025$ & $>2025$ & $>2025$ & $>2025$ & $>2025$ & $>2025$ & $>2025$ & $>2025$ & $>2025$ \\
\hline \multirow[t]{2}{*}{$\quad 1.50$} & & $>2025$ & $>2025$ & $>2025$ & $>2025$ & $>2025$ & $>2025$ & $>2025$ & $>2025$ & $>2025$ \\
\hline & . High & $>2025$ & $>2025$ & $>2025$ & $>2025$ & $>20.25$ & $>2025$ & $>2025$ & $>2025$ & $>2025$ \\
\hline \multirow[t]{2}{*}{1.25} & \multirow[t]{2}{*}{ Intermediațe } & $>2025$ & $>2025$ & $>2025$ & $>2025$ & $>2025$ & 2026 & $>2025$ & 2024 & 2021 \\
\hline & & 2022 & 2017 & 2014 & 2014 & 2011 & 2010 & 2008 & 2007 & 2006 \\
\hline
\end{tabular}

Date oì Economic Transition to the FBR from the LWR with $25 \%$ Improvement in $\mathrm{U}_{3} \mathrm{O}_{3}$ Utilization on the Once-Through Cycle with $0.2 \%$ Tails 
TABLE A-12

Installed Capacity In 2000 (GWe):

\begin{tabular}{|c|c|c|c|c|c|c|c|c|c|c|}
\hline \multirow{2}{*}{\multicolumn{2}{|c|}{ Growth Rate (GWe/yr): }} & \multicolumn{3}{|c|}{200} & \multicolumn{3}{|c|}{300} & \multicolumn{3}{|c|}{400} \\
\hline & & 10 & 15 & 20 & $\overline{10}$ & 15 & 20 & 10 & 15 & 20 \\
\hline Capital Cost & $\mathrm{U}_{3} \mathrm{O}_{8}$ Fric? & \multirow{2}{*}{$>2025$} & \multirow{2}{*}{$>2025$} & \multirow{2}{*}{$>2025$} & \multirow{2}{*}{$>2025$} & \multirow[t]{2}{*}{$>2025$} & \multirow{2}{*}{$>2025$} & \multirow{2}{*}{$>2025$} & \multirow{2}{*}{$>2025$} & \multirow{2}{*}{$>2025$} \\
\hline \multirow[t]{2}{*}{1.75} & \multirow{2}{*}{$\begin{array}{c}\text { Irtermediate } \\
\text { High }\end{array}$} & & & & & & & & & \\
\hline & & $>2025$ & $>2025$ & $>2025$ & $>2025$ & $>2025$ & $>2025$ & $>2025$ & $>2025$ & $>2025$ \\
\hline \multirow[t]{2}{*}{1.50} & Intermediate & $>2025$ & $>2025$ & $>2025$ & $>2025$ & $>2025$ & $>2025$ & $>2025$ & $>2025$ & $>2025$ \\
\hline & High & $>2025$ & 2024 & 2019 & 2021 & 2017 & 2016 & 2016 & 2014 & 2012 \\
\hline \multirow[t]{2}{*}{1.25} & \multirow[t]{2}{*}{ Intermediate } & $>2025$ & $>2025$ & 2022 & 2024 & 2020 & 2018 & 2019 & 2016 & 2014 \\
\hline & & 2016 & 2013 & 2010 & 2008 & 2007 & 2006 & 2001 & 2001 & 2001 \\
\hline
\end{tabular}

Date of Economic Transition to the FBR from the Standard Light Water Reactor on the Once-Through Cycle with $0.05 \%$ Tails 
TABLE A-13

Installed Capac1ty. In 2000 (GWe):

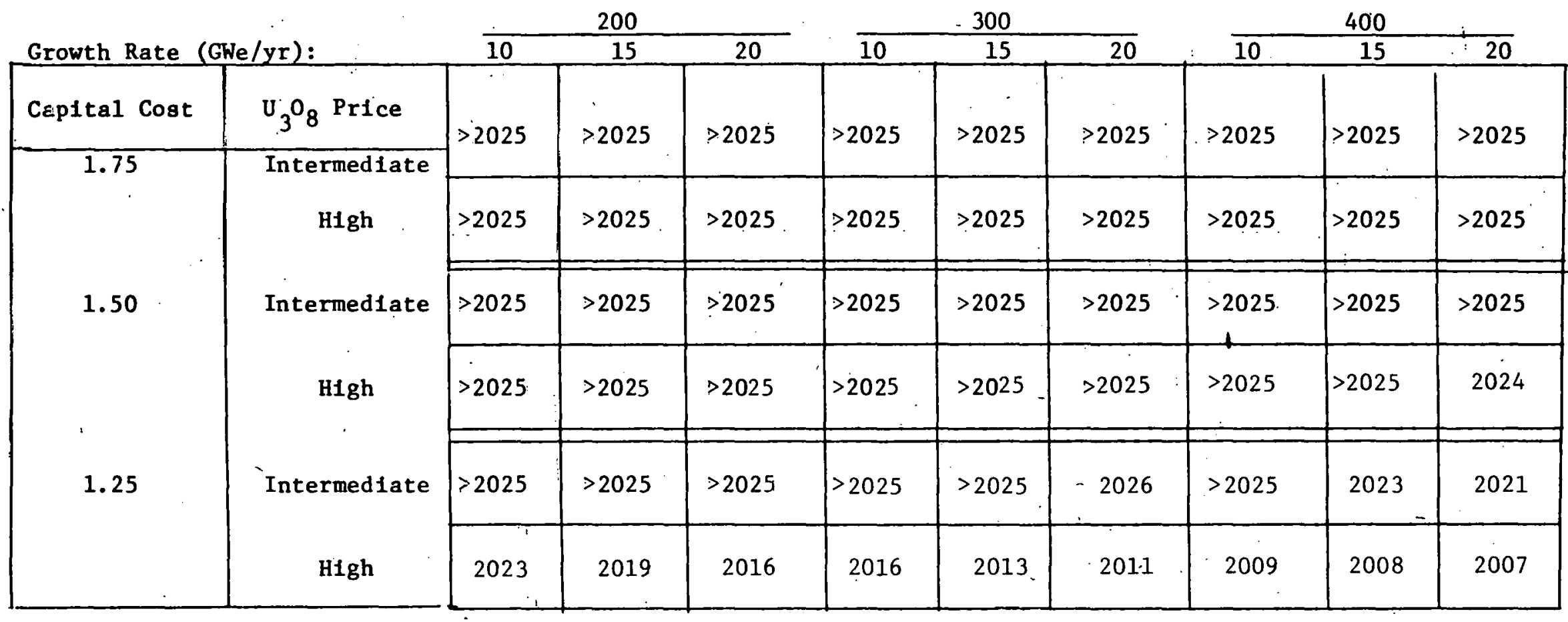

Date of Economic Transition to the FBR from the LWR with $25 \%$ Improvement in $\mathrm{U}_{3} 0_{8}$ Utilization on the Once-Through Cycle and with $0.05 \%$ Tails 
TABLE A-14

Insta:led Capacity In 2000 (GWe):

\begin{tabular}{|c|c|c|c|c|c|c|c|c|c|c|}
\hline \multirow{2}{*}{\multicolumn{2}{|c|}{ Growth Fate (GWe/ $/ \mathrm{Yr}$ ): }} & \multicolumn{3}{|c|}{200} & \multicolumn{3}{|c|}{300} & \multicolumn{3}{|c|}{400} \\
\hline & & 10 & 15 & 20 & 10 & 15 & 20 & 10 & 15 & 20 \\
\hline Capital Cost & $\mathrm{v}_{3} \mathrm{O}_{8}$ Price & \multirow{2}{*}{$>2025$} & \multirow{2}{*}{$\approx 2025$} & \multirow{2}{*}{$>2025$} & \multirow{2}{*}{$>2025$} & \multirow{2}{*}{$>2025$} & \multirow{2}{*}{$>2025$} & \multirow{2}{*}{$>2025$} & \multirow{2}{*}{$>2025$} & \multirow{2}{*}{$>2025$} \\
\hline \multirow[t]{2}{*}{1.75} & Intermed tace & & & & & & & & & \\
\hline & $\mathrm{H} 1 \mathrm{gh}$ & $>2025$ & $>2025$ & $>2025$ & $>2025$ & $>2025$ & $>2025$ & $>2025$ & $>2025$ & $>2025$ \\
\hline \multirow[t]{2}{*}{1.50} & Intermediate & $>2025$ & $>2025$ & $>2025$ & $>2025$ & $>2025$ & $>2025$ & $>2025$ & $>2025$ & $>2025$ \\
\hline & High & $>2025$ & $>2025$ & $>2025$ & $>2025$ & $>2025$ & $>2025$ & $>2025$ & $>2025$ & $>2025$ \\
\hline \multirow[t]{2}{*}{1.25} & Intermediate & $>2025$ & $>2025$ & $>2025$ & $>2025$ & $>2025$ & $>2025$ & $>2025$ & $>2025$ & $>2025$ \\
\hline & $\mathrm{HIgh}$ & $>2025$ & 2023 & 2019 & 2020 . & 2017 & 2014 & 2013 & 2012 & 2010 \\
\hline
\end{tabular}

Late of Eccnonic Transition to the FBR from the LWR with $25 \%$ Improvement in $\mathrm{U}_{3} 0_{\mathrm{R}}$ Utilization on the Once-Through Cycle and with $0.05 \%$ Tails 